NBER WORKING PAPER SERIES

THE PRODUCTION OF COGNITIVE AND NON-COGNITIVE HUMAN CAPITAL IN THE GLOBAL ECONOMY

\author{
Chong Xiang \\ Stephen Yeaple \\ Working Paper 24524 \\ http://www.nber.org/papers/w24524 \\ NATIONAL BUREAU OF ECONOMIC RESEARCH \\ 1050 Massachusetts Avenue \\ Cambridge, MA 02138 \\ April 2018, Revised February 2019
}

Chong Xiang gratefully acknowledges financial support from the Purdue University Research Center of Economics, or PURCE (2015). Stephen Yeaple's contribution to this paper was funded in part by National Science Foundation Research Grant (SES-1360209, 2014-2017). The views expressed herein are those of the authors and do not necessarily reflect the views of the National Bureau of Economic Research.

NBER working papers are circulated for discussion and comment purposes. They have not been peer-reviewed or been subject to the review by the NBER Board of Directors that accompanies official NBER publications.

(C) 2018 by Chong Xiang and Stephen Yeaple. All rights reserved. Short sections of text, not to exceed two paragraphs, may be quoted without explicit permission provided that full credit, including $(\odot$ notice, is given to the source. 
The Production of Cognitive and Non-cognitive Human Capital in the Global Economy

Chong Xiang and Stephen Yeaple

NBER Working Paper No. 24524

April 2018, Revised February 2019

JEL No. F16,F63,F66,I21,I25,I26,O15,O43,O47

\begin{abstract}
A country's welfare depends on its ability to accumulate cognitive and non-cognitive human capital. In this paper, we model the productions of cognitive and non-cognitive human capital in general equilibrium. We use revealed comparative advantage to infer countries' non-cognitive and cognitive productivities without a direct measure for the non-cognitive dimension. Our model also delivers analytical expressions for how non- cognitive and cognitive productivities can be aggregated into a single human-capital quality index, or HCQI, and how HCQI relates to output per worker.

Our model allows us to obtain the values of non-cognitive and cognitive productivities and HCQI, using publically available data for a sample of mostly high-income countries. We find that: 1 . many countries with low test scores have high non-cognitive productivities; 2 . the hardto-measure non-cognitive human capital is important for HCQI, and HCQI is important for output per worker; 3 . the trade-o a between cognitive- and non-cognitive productivities can be visualized and analyzed using an iso-HCQI curve: e.g. uneven cognitive and non-cognitive productivities tend to lower HCQI; 4. this trade-o can be quantified, and has policy implications: e.g. excessive attention to test scores may decrease aggregate output; 5. international trade matters, theoretically, for HCQI, because the gains from trade help to compensate a country for uneven productivity across human capital types: e.g. the iso-HCQI curve would have a very different shape under free trade.
\end{abstract}

Chong Xiang

Department of Economics

Purdue University

403 West State Street

West Lafayette, IN 47907-2506

cxiang@purdue.edu

Stephen Yeaple

Department of Economics

The Pennsylvania State University

520 Kern Building

University Park, PA 16802-3306

and NBER

sry3@psu.edu 


\title{
The Production of Cognitive and Non-cognitive Human Capital in the Global Economy
}

\author{
Chong Xiang, Purdue University \\ Stephen Ross Yeaple, Penn State University and NBER
}

January 2019

\begin{abstract}
A country's welfare depends on its ability to accumulate cognitive and non-cognitive human capital. In this paper, we model the productions of cognitive and non-cognitive human capital in general equilibrium. We use revealed comparative advantage to infer countries' non-cognitive and cognitive productivities without a direct measure for the non-cognitive dimension. Our model also delivers analytical expressions for how noncognitive and cognitive productivities can be aggregated into a single human-capital quality index, or HCQI, and how HCQI relates to output per worker.

Our model allows us to obtain the values of non-cognitive and cognitive productivities and HCQI, using publically available data for a sample of mostly high-income countries. We find that: 1 . many countries with low test scores have high non-cognitive productivities; 2. the hard-to-measure non-cognitive human capital is important for HCQI, and HCQI is important for output per worker; 3. the trade-off between cognitive- and non-cognitive productivities can be visualized and analyzed using an iso-HCQI curve: e.g. uneven cognitive and non-cognitive productivities tend to lower HCQI; 4. this trade-off can be quantified, and has policy implications: e.g. excessive attention to test scores may decrease aggregate output; 5 . international trade matters, theoretically, for HCQI, because the gains from trade help to compensate a country for uneven productivity across human capital types: e.g. the iso-HCQI curve would have a very different shape under free trade.
\end{abstract}

\section{Introduction}

Human capital is central to both economics and other social sciences, and so it is important to understand how well countries produce their human capital. A large body of work quantifies human capital for cross-country comparison (e.g. Mankiw, Romer and Weil 1992, Barro 
and Sala-i-Martin 1995, Klenow and Rodriguez-Clare 1997, Hall and Jones 1999, Bils and Klenow 2000, Hendricks 2002, Caselli 2005, Caselli and Coleman 2006, Erosa, Koreshkova and Restuccia 2010, Schoellman 2012, Jones 2014, Manuelli and Seshadri 2014, Malmberg 2017). These studies consider a single type of human capital. ${ }^{1}$

Human capital, however, is multi-dimensional. Consider scores on international assessment tests, an often-used metric for human capital in the literature (e.g. Hanushek and Kimko 2000, Hanushek and Woessmann 2011, Cubas, Ravikumar and Ventura 2016). The best known of these tests is PISA. The U.S.' low PISA scores have alarmed policy makers ${ }^{2}$ and motivated major policy changes (e.g. No Child Left Behind of 2001 and Race to the Top of 2009) in the U.S. Like the U.S., many other countries worry that their test scores are too low (e.g. U.K., Slovakia and Qatar). ${ }^{3}$

Oddly, many countries whose students excel in international exams worry that their test scores are too high! i.e. their educational systems overemphasize formal examination proficiency, and their students spend too much time studying for exams. ${ }^{4}$ This concern has also influenced policy; e.g. the Education Ministry in China declared a ban on homework assignments for young children in August 2013, and South Korea declared a 10 pm curfew on private tutoring. The fear is that the educational systems emphasize testing to such a degree that students do not effectively develop soft, or non-cognitive, skills, such as leadership, cooperation, and communication.

The multi-dimensionality of human capital poses challenges for researchers; e.g. how to quantify multiple types of human capital, and what is the appropriate aggregation? If the policy implication is to increase human capital, which type to increase? On top of these, the second dimension is non-cognitive. While the importance of non-cognitive skills has been clearly established (e.g. Heckman and Rubinstein 2001), many of them do not show up in test scores (e.g. Heckman and Kautz 2012). Hanushek and Woessmann (2011) recognize that "the systematic measurement of such skills has yet to be possible in international comparisons". Lundberg (2017) agrees that "we are far ... from a clear understanding of how to ... measure non-cognitive skills in a way that would allow for meaningful cross-country analysis". ${ }^{5}$

\footnotetext{
${ }^{1}$ The focus on a single type of human capital is also common for other literatures. e.g. the studies on how international trade affects skill acquisition examine years of schooling (e.g. Findlay and Kierzkowski 1983, Atkin 2016, Li 2016, Blanchard and Olney 2017).

${ }^{2}$ e.g. President Obama said that the nation that "out-educates us today will out-compete us tomorrow."

${ }^{3}$ For example, in February 2014, Elizabeth Truss, the U.K. education minister, visited Shanghai, China, whose test score is much higher than the U.K.'s, to "learn a lesson a math".

${ }^{4}$ For example, the Wall Street Journal reports that "A typical East Asian high school student often must follow a 5 a.m. to midnight compressed schedule, filled with class instruction followed by private institute courses, for up to six days a week, with little or no room for socializing" (February 29, 2012), and that "many students prepare for [the national college] entrance exams from an early age, often studying up to 16 hours a day for years to take these tests" (November 10, 2011).

${ }^{5}$ An example for this challenge is Schmitt, Allik, McCrae and Benet-Martinez (2007), who conduct a
} 
In this paper, we take a first step in answering these questions. We develop a general equilibrium (GE) framework to quantify how countries produce human capital along multiple dimensions. Our model is based on two intuitive premises. The first premise is that peoples' occupational choices reveal information about their skills at different types of tasks, and these skills reflect different types of human capital. For example, a manager issues directions and guidance to subordinates, while a secretary follows these orders and an engineer uses the knowledge in math and science to solve problems. Intuitively, this allows us to infer a country's comparative advantage in fostering non-cognitive relative to cognitive human capital from occupational choice data. The second premise is that countries' performances on international exams are informative about their cognitive human capital.

Our model then allows us to combine these two elements to infer countries' productivities for both non-cognitive and cognitive human capital. In other words, we are able to make cross-country comparisons for the non-cognitive dimension, without a direct measure for this dimension. Intuitively, this is because revealed comparative advantage allows us to lean on the measure for the cognitive dimension (test score) using occupational choice data. Our model also allows us to aggregate the multi-dimensional differences in cognitive and noncognitive productivities into a single metric, which we call human-capital quality index, or HCQI.

The main elements of our framework are as follows. We write down the production functions of cognitive and non-cognitive human capital, where output (efficiency-equivalent units of human capital) depends on resources inputs and TFP (Total Factor Productivity). TFP differs across the two types of human capital, and also across countries. These TFP parameters are countries' cognitive and non-cognitive productivities.

We have heterogeneous workers make optimal decisions about which types of human capital to invest in, and how much. ${ }^{6}$ They do so given their own comparative advantages in non-cognitive and cognitive skills, as in Willis and Rosen (1979), which, in turn, are determined by their innate abilities at birth and by the human capital that they accumulated. When workers decide how much human capital to obtain, they factor in the returns of human capital on the labor market, recognizing that non-cognitive and cognitive occupations require different types of human capital. This implies that in our model, individual workers' human capital accumulation is affected by their occupational choices, which, in turn, depend on

cross-country survey of conscientiousness. The top nations for conscientiousness turn out to be Ethiopia and the Democratic Republic of Congo, while the bottom ones include Japan and S. Korea.

${ }^{6} \mathrm{We}$ do so because researchers have long recognized that incentives matter for educational outcomes, which is closely related to human capital production. Heckman and Kautz (2012) survey earlier studies, which show that incentives, in the form of money or even candy, improve the scores of IQ tests. In more recent work, Behrman, Parker, Todd, and Wolpin (2015) show that providing monetary incentives to Mexican high-school students has substantial and immediate effects on their test scores. 
the non-cognitive and cognitive productivities of the economy. It then follows that this comparative advantage is revealed by the ratio of occupation employment shares. Intuitively speaking, the fact that many individuals in country $k$ choose the non-cognitive occupation suggests that country $k$ has a strong comparative advantage for non-cognitive human capital.

If, in addition, country $k$ has a high cognitive productivity, then this country must also have a high non-cognitive productivity. For cognitive productivities we use test scores as the starting point, and remove the confounding factors of resources inputs and incentives under the guidance of our GE model.

Our GE model shows that HCQI is the weighted power mean of cognitive and noncognitive productivities, the weights being the employment shares of cognitive and noncognitive occupations. The power coefficients of HCQI depend on both the supply elasticity, which is governed by the dispersion of workers' innate abilities, and the demand elasticity, which is the substitution-elasticity across different types of human capital in aggregate production. In addition, the ratio of output per worker between any pair of countries can be decomposed into a power function of HCQI, multiplied by a power function of the ratio of output TFP. In other words, HCQI is the right index to quantify human capital according to our model.

We then infer the values of non-cognitive and cognitive productivities and compute HCQI, using publically available data for a sample of mostly high-income countries. Our theoretical and empirical results provide the following new perspectives.

First, countries' rankings in non-cognitive and cognitive productivities are substantially different from their PISA-score rankings. In particular, countries' non-cognitive-productivity rankings have zero correlation with their PISA score rankings, many countries with low test scores have high non-cognitive productivities (e.g. the U.S. and U.K.), and those with the highest test scores do not necessarily have the highest cognitive productivities (e.g. S. Korea, Hong Kong).

Second, test scores are not informative about countries' differences in HCQI, either, because most variation in HCQI comes from the non-cognitive dimension. In addition, these differences in HCQI are economically significant. e.g. France's HCQI is lower than the U.S., the effect of which (according to our model) puts France's output per worker at $91.15 \%$ of the U.S. level.

Third, we graph the combinations of cognitive and non-cognitive productivities that produce the same HCQI. This iso-HCQI curve allows us to visualize and analyze the tradeoff between cognitive and non-cognitive productivities in terms of overall quality. Specifically, the countries with imbalanced human capital productivities, such as Portugal and S. Korea, tend to have low HCQI. In addition, we can quantify this trade-off using our model. e.g. a $1 \%$ increase in U.S. cognitive productivity increases her output by $0.85 \%$, but this payoff 
shrinks to 0 if her non-cognitive productivity decreases by $2.95 \%$.

Fourth, this trade-off has policy implications; e.g. test score and aggregate output may move in opposite directions in our model. This is because test score primarily reflects cognitive human capital, whereas both types of human capital are important for HCQI and so aggregate output. e.g. a $1 \%$ increase in U.S. non-cognitive productivity increases U.S. output by $0.29 \%$, but decreases her test score by $0.05 \%$. This message resonates with a large body of applied-micro studies on early childhood intervention programs in the U.S. ${ }^{7}$ Here, a common finding is that the programs boost participants' adult outcome (e.g. higher wages), but have little long-term effects on their test scores. Quoting Chetty et al. (2011), the results "suggest that policy makers may wish to rethink the objective of raising test scores and evaluating interventions via long-term test score gains".

Fifth, international trade matters, in theory. e.g. under free trade, the power coefficients of HCQI depend only on the supply elasticity, not on the demand elasticity. Intuitively, this is because countries are no longer constrained by local labor-market demand, and imbalance in human-capital productivities helps countries specialize and enjoy gains from trade. We show that the iso-HCQI curve would have a very different shape under free trade. We also show that the countries with strong comparative advantages (e.g. S. Korea, the Netherlands) would see large changes in HCQI and enjoy large welfare gains under free trade. ${ }^{8}$ On the other hand, in the open-economy setting with trade costs, the effects of trade are summarized by its factor content in terms of cognitive and non-cognitive human capital. Looking at our data, we find small values of factor content trade, consistent with previous studies. ${ }^{9}$

Finally, we provide two external validations for the values of our non-cognitive productivities and HCQI. First, we show that HCQI has more positive correlation with output per worker than PISA score in our data. This is intuitive: test score mainly captures cognitive human capital, and HCQI captures some non-cognitive human capital that test score has missed. Second, we show that the countries with strong comparative advantages for noncognitive human capital tend to have high normalized net exports of non-cognitive-intensive industries. This is also intuitive: cognitive and non-cognitive productivities are about the supply of human capital, and abundance in relative supply shows up in the patterns of trade.

We now further clarify how our study complements previous work. Erosa et al. (2010),

${ }^{7}$ For the Head Start program, see Garces, Thomas and Currie (2002), Ludwig and Miller (2007), Deming (2009), and U.S. DHHS 2010. For Perry, see Schweinhart et al. (2005) and Heckman et al. (2010). For Star, see Chetty, Friedman, Hilger, Saez, Schanzenbach and Yagan (2011). Recent surveys include Duncan and Magnuson (2013) and Heckman and Kautz (2013).

${ }^{8}$ We derive an analytical expression relating the change in HCQI to countries' gains from trade. It is a conservative estimate of gains from trade, because we abstract away from product differentiation and intraindustry trade, which have been extensively studied in the trade literature (e.g. Costinot and Rodriguez-Clare 2012, or ACR 2012).

${ }^{9}$ e.g. Trefler (1995), Davis and Weinstein (2001), and Costinot and Rodriguez-Clare (2014). 
Manuelli and Seshadri (2014) and Cubas et al. (2016) model the production of one type of human capital, making the point that human-capital production can amplify small differences in output TFP. We model the production of multiple types of human capital and carry out theoretical explorations and empirical quantifications of HCQI, abstracting away from many amplification mechanisms.

Hsieh and Klenow (2009) and Hsieh, Hurst, Jones and Klenow (2018) investigate how market frictions for capital, final goods and labor distort resource allocation and output, using micro data from China, India, and the U.S. We focus on cross-country comparisons of non-cognitive and cognitive productivity and HCQI, and abstract away from market frictions and distortion in our model.

Caselli and Coleman (2006), Jones (2014) and Malmberg (2017) examine imperfect substitutability among workers with different schooling years. These studies abstract away from the production of human capital, and the key parameter there is the substitution elasticity in aggregate production. We model human-capital production, and so HCQI depends on both supply and demand elasticities. We abstract away from imperfect substitutability within a given type of human capital.

Like our study, Ohsornge and Trefler (2007), Lagakos and Waugh (2013), Burnstein, Morales and Vogel (2016) and Lee (2017) model heterogeneous workers making optimal choices across occupations (or industries). On the other hand, these studies abstract away from human-capital production, which is the focus of our study.

An applied micro literature examines the formation of cognitive and non-cognitive skills using worker-level data from a single country (e.g. Kuhn and Weinberger 2005, Cunha, Heckman and Schennach 2010, Jackson, Johnson and Persico 2015). We take a macro perspective by quantifying the ways in which different countries produce multiple types of human capital, and then clarifying the implications of such differences for aggregate output in a GE model.

More broadly, the ways countries produce their human capital are related to their educational systems, which often have deep historic roots and so are an important part of their institutions. We thus also contribute to the institutions literature (e.g. Acemoglu, Johnson and Robinson 2001) by quantifying key characteristics of the educational institution and their implications for aggregate output.

For the remainder of our paper, section 2 clarifies how we group occupations into noncognitive and cognitive. Section 3 spells out our theoretical framework, and section 4 explains how it makes contact with macro data. Section 5 examines falsifiable predictions of our model and obtains the values of our parameters. Section 6 presents our results and draws out their policy implications. Section 7 extends our model to open economy, and section 8 collects additional extensions and robustness exercises. Section 9 concludes, and discusses 
implications for future research.

\section{Non-cognitive and Cognitive Occupations}

A large literature has examined many non-cognitive skills, without reaching a consensus about which should be the standard measure(s). ${ }^{10}$ However, there is a common approach: this literature typically uses surveys or occupation-characteristics data sets, such as the U.S. O*NET, to proxy for non-cognitive skills and provides empirical evidence that these measures are different from the measures of cognitive skills.

We follow this approach, and use leadership to measure non-cognitive occupations. According to our first classification, an occupation is non-cognitive if the $\mathrm{O}^{*} \mathrm{NET}$ characteristic "providing guidance and direction to subordinates ..." is important for that occupation, and we classify all the other occupations as cognitive. For our second metric, we classify occupations on the basis of the first principal component of the following $8 \mathrm{O}^{*} \mathrm{NET}$ characteristics of leadership: guiding and directing subordinates; leadership in work style; coordinating the work and activities of others; developing and building teams; coaching and developing others; recruiting and promoting employees; monitoring and controlling resources and spending; and coordinate or lead others in work (see Data Appendix 1 for more details).

To be clear, we are not proposing leadership as the measure for non-cognitive human capital. Rather, we demonstrate that leadership is a useful measure; i.e. it captures some skills that are not well measured by test score, and it is also useful for cross-country comparison. We show the first point in this section, using micro data, and show the second point in section 5 below, using macro data.

We now demonstrate that the two occupational categories that we have created differ in the extent to which performance on test scores matters for workplace productivity. A large literature shows that individuals' AFQT (Armed Force Qualification Test) scores are strongly correlated with their wages (e.g. Neal and Johnson 1996, Altonji and Pierret 2001). We use this framework to show that the wages of leadership occupations are less correlated with test scores than those of the other occupations.

The data used in Table 1 is the 1979 NLSY (National Longitudinal Survey of Youth). The dependent variable is the log of individuals' wages in 1991, and the main explanatory variable is their AFQT score in 1980, before they enter the labor force. Column 1 shows that the coefficient estimate of AFQT score is positive and significant, and this result replicates

\footnotetext{
${ }^{10}$ Examples include communications (e.g. Hummels, Jorgensen, Munch and Xiang 2014), grit (e.g. Almlund, Duckworth, Heckman and Kautz 2011), leadership (e.g. Kuhn and Weinberger 2005), self-esteem (e.g. Heckman and Rubinstein 2001), and social skills (e.g. Deming 2017). Recent surveys include Heckman and Kautz (2013) and Lundberg (2017).
} 
Neal and Johnson (1996). ${ }^{11}$ Columns 2 and 3 show that AFQT score has a smaller coefficient estimate for the subsample of non-cognitive occupations than for the subsample of cognitive occupations, ${ }^{12}$ where we classify non-cognitive occupations using the leadership principal component. To show this pattern more rigorously, we pool the data in column 4 and introduce the interaction between AFQT score and the non-cognitive-occupation dummy. The coefficient estimate of this interaction term is negative and significant. ${ }^{13}$ Column 5 uses guiding-and-directing-subordinates to classify non-cognitive occupations, and obtains similar results. In column 6 we use the O*NET characteristic of enterprising skills as another alternative measure for leadership. The interaction between enterprising skills and AFQT score is negative but not significant.

In section 8 below, we examine additional $\mathrm{O}^{*} \mathrm{NET}$ characteristics as candidates for occupation classification, and show that they do not exhibit the correlation patterns in Table 1 .

Having classified occupations as non-cognitive and cognitive, we next bring in employment data by 3- or 4-digit occupations from the International Labor Organization (ILO) (more details are in Data Appendix 3) to show that countries differ in the extent to which their workforces have accumulated cognitive versus non-cognitive skills. We keep only the countries whose raw data are in ISCO-88 (International Standard Classification of Occupations), because $\mathrm{O}^{*} \mathrm{NET}$ occupations can be easily mapped into ISCO-88 occupations but the mappings among other occupation codes are very scarce (e.g. we cannot find the mapping between Canadian and U.S. occupation codes). ${ }^{14}$ This leaves us with a cross-section of 34 countries, and most of the observations are for the year 2000. Examples of non-cognitive occupations include business professionals (ISCO-88 code 2410), managers of small enterprises (1310), building frame and related trades workers (7120), nursing and midwifery professionals (3230), etc. Examples for cognitive occupations include architects, engineers and related professionals (2140), finance and sales professionals (3410), secretaries (4110), motor vehicle drivers (8320), etc. We show the variation of the employment share of non-cognitive occupations across our sample countries by plotting its histogram in Figure 1.

In this section, we have shown that occupations differ in terms of the nature of the human capital required, and that countries differ in the occupational composition of their workforce.

\footnotetext{
${ }^{11}$ We include both men and women in Table 1, while Neal and Johnson (1996) do the estimation separately for men and women. We have experimented with this and obtained very similar results. We also use the same sample cuts as Neal and Johnson (1996) (Data Appendix 2).

${ }^{12}$ Note that the coefficient estimates for AFQT square are not significant.

${ }^{13}$ Note that we have included the non-cognitive dummy itself, plus the college dummy and its interaction with AFQT score, as additional controls.

${ }^{14}$ The statistical agencies of Australia and New Zealand provided us with mappings from their (2-digit) national occupation codes to ISCO-88, and we include them in our sample as well. We obtain very similar results when we drop them.
} 
In the next section, we provide an analytical method for aggregating multiple types of human capital.

\section{A Model of HCQI}

In this section we develop a stylized model, a key feature of which is that heterogeneous workers optimally choose their investment in both the quantities and types of human capital. Our model delivers an analytical expression for HCQI, and shows that it is closely related to output per worker. We start with the closed-economy setting, and provide the open-economy extension in section 7 .

\subsection{Model Structure}

There are $K$ countries, indexed by $k$, each endowed with $L^{k}$ heterogeneous workers. Workers are endowed with non-cognitive and cognitive attributes $\varepsilon_{n}$ and $\varepsilon_{c}$, drawn from the following Frechet distribution:

$$
F\left(\varepsilon_{n}, \varepsilon_{c}\right)=\exp \left(-\left(T_{c} \varepsilon_{c}^{-\theta}+T_{n} \varepsilon_{n}^{-\theta}\right)^{1-\rho}\right), \theta \equiv \frac{\tilde{\theta}}{1-\rho} .
$$

In the context of the correlation patterns that we discussed in section 2 , we think about the attributes $n$ and $c$ as two distinct packages of skills, rather than two individual skills, and these two packages may have common elements. We formalize these points in section 8 below.

In equation (1), the parameter $\rho$ captures the degree to which non-cognitive and cognitive packages are correlated. ${ }^{15}$ The parameter $\theta$ captures the dispersion of attributes across workers. As $\theta$ rises, the distribution becomes more compressed, and so there is less worker heterogeneity. Note that for the distribution to have finite variance, we require $\theta>1$. Finally, $T_{c}$ and $T_{n}$, both positive, capture the locations of the attributes distribution; e.g. as $T_{c}$ rises, the distribution of cognitive abilities shifts to the right, so that the average worker has better innate cognitive abilities.

Following Hsieh et al. (2018), we specify the following production function for human capital of type $i, i=n$ (non-cognitive) or $c$ (cognitive)

$$
h_{i}(e)=h_{i}^{k} e^{\eta}, i=c, n \text {. }
$$

In equation (2), $e$ is an individual worker's spending on human capital accumulation, in units of the final good (we specify its production below). The parameter $\eta$ captures decreasing

\footnotetext{
${ }^{15}$ When $\rho=0$, they are independent; when $\rho>0$, they have positive correlation; and when $\rho \rightarrow 1$, they become perfectly collinear.
} 
returns in the production of human capital, and guarantees an interior solution for workers' optimal choice of $e$. The parameters $h_{n}^{k}$ and $h_{c}^{k}$ are country $k$ 's TFP's in the production functions of non-cognitive and cognitive human capital, and they capture country $k$ 's human capital productivities along these two dimensions, net of resources inputs.

We treat $h_{n}^{k}$ and $h_{c}^{k}$ as exogenous, because the educational institution, an important contributor to human capital production, has deep historic roots in many countries. For example, in the U.S., private universities and colleges are a main feature of the educational institution, and their legal rights and status were enshrined by the Supreme Court in 1819 in Dartmouth-College-vs-Woodward. ${ }^{16}$ In S. Korea, and many other East Asian countries, the national exam has been a cornerstone of the educational institution for over 1,000 years. ${ }^{17}$ We capture, and quantify, such cross-country differences in educational institutions as $h_{n}^{k}$ and $h_{c}^{k}$, and so we place no restriction on their values. On the other hand, we assume that $\rho, \theta, \eta, T_{c}$, and $T_{n}$ do not vary across countries. ${ }^{18}$

Both non-cognitive and cognitive tasks are needed to produce the final good. When a worker chooses task i, or occupation i, her output is

$$
h_{i}(e) \varepsilon_{i}, i=n, c
$$

where $h_{i}(e)$ is the quantity of the worker's human capital, accumulated according to the technology (2), and $\varepsilon_{i}$ her attribute, drawn from the distribution in (1). ${ }^{19}$ The educational and occupational choices made by workers lead to aggregate supplies of cognitive and noncognitive human capital in country $k$ of $L_{c}^{k S}$ and $L_{n}^{k S}$ (hence the $S$ superscript), respectively.

\footnotetext{
${ }^{16}$ In 1816, New Hampshire enacted state law to convert Dartmouth College from a private institution to a state institution. The case went to the U.S. Supreme Court, the legal issue being whether Dartmouth's original charter with the King of England should be upheld after the American Revolution. In 1819, the Supreme Court sided with Dartmouth, and this decision also guaranteed the private status of other early colonial colleges, such as Harvard, William and Mary, Yale, and Princeton (e.g. Webb, Metha, and Jordan 2013).

${ }^{17}$ China used archery competitions to help make promotion decisions for certain bureaucratic positions before 256 B.C.E., and established the imperial examination system as early as 605 A.D., which remained in use for over 1,000 years. In this system, one's score in the national exam determines whether or not he is appointed as a government official, and if so, his rank. Through trade, migration, and cultural exchanges, China's imperial examination system spread to neighboring countries; e.g. Korea established a similar system in 958 A.D. (Seth, 2002).

${ }^{18}$ The assumption about $\rho, \theta$ and $\eta$ is standard in the literature. Our intuition for the assumption about $T_{c}$ and $T_{n}$ is that genetic differences across countries have no significant effects on birth talents. It is reasonable to imagine that severe malnutrition could change the T's. As we will consider a sample of primarily middle and upper income countries, this issue is less of a concern.

${ }^{19}$ Equation (3) assumes that occupation $i$ uses skill $i$. In section 8 we have both occupations use both skills, with occupation $i$ being more intensive in skill $i$. This alternative specification delivers very similar results.
} 
The representative firm hires workers in both cognitive and non-cognitive occupations to maximize output

$$
Y^{k}=\Theta^{k}\left(A_{c}\left(L_{c}^{k D}\right)^{\frac{\alpha-1}{\alpha}}+A_{n}\left(L_{n}^{k D}\right)^{\frac{\alpha-1}{\alpha}}\right)^{\frac{\alpha}{\alpha-1}}
$$

In equation (4), $\Theta^{k}$ is country $k$ 's output TFP, and $A_{c}$ and $A_{n}$ common technological parameters. The parameter $\alpha>0$ is the substitution elasticity between non-cognitive and

cognitive skills. $L_{n}^{k D}$ and $L_{c}^{k D}$ are the aggregate levels of non-cognitive and cognitive human capital demanded (hence the $D$ superscript) by final goods producers in country $k$.

The key prices in country $k$ are the price of an effective unit of cognitive human capital, $w_{c}^{k}$, the price of an effective unit of non-cognitive human capital, $w_{n}^{k}$, and the price of the final output, $P^{k}$. Given cost minimization of the perfectly competitive final goods producers, the price of the final good (4) is given by

$$
P^{k}=\frac{1}{\Theta^{k}}\left(\left(A_{c}\right)^{\alpha}\left(w_{c}^{k}\right)^{1-\alpha}+\left(A_{n}\right)^{\alpha}\left(w_{n}^{k}\right)^{1-\alpha}\right)^{\frac{1}{1-\alpha}} .
$$

Equation (5) says that $P^{k}$ varies across countries because $w_{c}^{k}$ and $w_{n}^{k}$ may vary across countries. In addition, a country with high output TFP tends to enjoy low price of the final good, ceteris paribus.

All markets are perfectly competitive. The timing happens as follows. First, workers choose how much and what type (cognitive or non-cognitive) of human capital to obtain. Second, final goods producers choose how many workers of each type to employ. Finally, all markets clear.

\subsection{Equilibrium Conditions}

We first analyze individual workers' optimal choices for the quantity and type of human capital accumulation. We then aggregate across individuals to obtain the aggregate supplies of cognitive and non-cognitive human capital in country $k$, and bring in the demand side and characterize the equilibrium.

Recall that human capital investment is in terms of final output. This means that the proper maximization problem facing an individual that will choose occupation $i$ is

$$
\max _{e}\left\{w_{i} h_{i}^{k} e^{\eta} \epsilon_{i}-P^{k} e\right\}
$$

and so the optimal choice of human capital investment is

$$
e\left(\epsilon_{i}\right)=\left(\eta \frac{w_{i}^{k}}{P^{k}} h_{i}^{k} \epsilon_{i}\right)^{\frac{1}{1-\eta}}
$$

In equation (6), e $\left(\epsilon_{i}\right)$ is the quantity of human capital investment. Equation (6) says that, intuitively, gifted individuals, of both occupations, make large quantities of human capital 
investment. In addition, individuals in country $k$ also have large quantities of human capital investment if real wages are high.

We now plug the worker' optimal choice in (6) into her maximization problem, and obtain the following expression for her optimal net income in occupation $i$,

$$
I_{i}\left(\varepsilon_{i}\right)=(1-\eta) \eta^{\frac{\eta}{1-\eta}}\left(\frac{w_{i}^{k}}{P^{k}} h_{i}^{k} \varepsilon_{i}^{k}\right)^{\frac{1}{1-\eta}} .
$$

Equation (6) and (7) show that net income, $I_{i}\left(\varepsilon_{i}\right)$, is proportional to human-capital spending, $e_{i}\left(\varepsilon_{i}\right)$. In addition, (6) and (7) show that the final-good price index, $P^{k}$, has the same effects on $e\left(\epsilon_{i}\right)$ and $I_{i}\left(\varepsilon_{i}\right)$ for both occupations. This means that $P^{k}$ does not affect individuals' occupational choices, which are based on their comparative advantages. To be specific, equation (7) implies that the worker chooses occupation $n$ if and only if $w_{c}^{k} h_{c}^{k} \varepsilon_{c}^{k} \leq w_{n}^{k} h_{n}^{k} \varepsilon_{n}^{k}$. This is a classic discrete-choice problem (e.g. McFadden 1974). Using the Frechet distribution (1), we show that the employment share of occupation $i$ equals (Theory Appendix 1)

$$
p_{i}^{k}=\frac{T_{i}\left(w_{i}^{k} h_{i}^{k}\right)^{\theta}}{T_{c}\left(w_{c}^{k} h_{c}^{k}\right)^{\theta}+T_{n}\left(w_{n}^{k} h_{n}^{k}\right)^{\theta}}, i=c, n .
$$

Equation (8) says that the non-cognitive employment share, $p_{n}^{k}$, is high, if workers have a strong comparative advantage in non-cognitive innate abilities (high $T_{n} / T_{c}$ ), non-cognitive skills have a high relative return in the labor market (high $w_{n}^{k} / w_{c}^{k}$ ), or country $k$ has a strong comparative advantage in fostering non-cognitive human capital (high $h_{n}^{k} / h_{c}^{k}$ ). In (8), $\theta$ plays an important role. As $\theta$ rises and workers become more homogeneous, given changes in $w_{i}^{k}$ or $h_{i}^{k}$ lead to bigger shifts in the proportion of workers that opt to work in different occupations. Equation (8) characterizes individuals' optimal choices for the types of human capital accumulated, and plays a key role in our model.

To solve the model, we start by calculating the average net income of non-cognitive and cognitive workers, which analytically involves taking the expected value of equation (7), with respect to $\varepsilon_{i}$, conditional on type $i, i=n, c$. We show that the average net income is the same for non-cognitive and cognitive workers; i.e. (Theory Appendix 2)

$$
\begin{aligned}
I_{n}^{k} & =I_{c}^{k}=\gamma(1-\eta) \eta^{\frac{\eta}{1-\eta}}\left[T_{c}\left(\frac{w_{c}^{k}}{P^{k}} h_{c}^{k}\right)^{\theta}+T_{n}\left(\frac{w_{n}^{k}}{P^{k}} h_{n}^{k}\right)^{\theta}\right]^{\frac{1}{\theta(1-\eta)}}, \\
\text { where } \gamma & =\Gamma\left(1-\frac{1}{\theta(1-\rho)(1-\eta)}\right) .
\end{aligned}
$$

Equation (9) is a common feature of the solution to discrete choice problems with Frechet distribution and homothetic demand (e.g. Eaton and Kortum 2002). In (9), the term in the square brackets is proportional to the denominator of the employment-share expression, (8). $\Gamma($.$) is the Gamma function and so \gamma$ is a constant. 
Equations (8) and (9) imply that the average educational expenditure is equalized for non-cognitive and cognitive workers:

$$
E_{n}^{k}=E_{c}^{k}=\gamma\left[\eta\left(T_{c}\left(\frac{w_{c}^{k}}{P^{k}} h_{c}^{k}\right)^{\theta}+T_{n}\left(\frac{w_{n}^{k}}{P^{k}} h_{n}^{k}\right)^{\theta}\right)^{\frac{1}{\theta}}\right]^{\frac{1}{1-\eta}}
$$

By equation (10), we now use $E^{k}$, without an occupation subscript, to denote the average educational spending in country $k .^{20}$ Equation (10) will prove useful in pinning down $\eta$, the elasticity of the output of human capital with respect to input, as we show in section 5 .

We now solve for the aggregate supply of human capital of type $i, L_{i}^{k S}, i=n, c$, and obtain (Theory Appendix 3):

$$
L_{i}^{k S}=L^{k} p_{i}^{k} E\left(h_{i}^{k} e^{\eta} \mid O c c p . i\right)=\frac{L^{k} p_{i}^{k}}{w_{i}^{k}}\left(\eta^{\eta}\left(P^{k}\right)^{1-\eta}\left(T_{c}\left(\frac{w_{c}^{k}}{P^{k}} h_{c}^{k}\right)^{\theta}+T_{n}\left(\frac{w_{n}^{k}}{P^{k}} h_{n}^{k}\right)^{\theta}\right)^{\frac{1}{\theta}}\right)^{\frac{1}{1-\eta}} \gamma
$$

Equation (11), together with $w_{c}^{k} L_{c}^{k}+w_{n}^{k} L_{n}^{k}=P^{k} Y^{k}$, implies that the income shares of cognitive and non-cognitive workers are given by

$$
\frac{w_{i}^{k} L_{i}^{k S}}{P^{k} Y^{k}}=p_{i}^{k} .
$$

To complete our characterization of the supply side of the economy, we use equations (8) and (11) to derive the relative supply of non-cognitive human capital, which is given by

$$
\frac{w_{n}^{k}}{w_{c}^{k}} \frac{L_{n}^{k S}}{L_{c}^{k S}}=\frac{p_{n}^{k}}{p_{c}^{k}} \text { where } \frac{p_{n}^{k}}{p_{c}^{k}}=\frac{T_{n}\left(w_{n}^{k} h_{n}^{k}\right)^{\theta}}{T_{c}\left(w_{c}^{k} h_{c}^{k}\right)^{\theta}}
$$

Equation (13) says that the relative supply of non-cognitive labor, $L_{n}^{k S} / L_{c}^{k S}$, is increasing in the availability of raw talent in the country, the comparative advantage of that country in non-cognitive human capital, $h_{n}^{k} / h_{c}^{k}$, and the relative return of non-cognitive human capital, $w_{n}^{k} / w_{c}^{k}$. As foreshadowed by our discussion of equation (8), it is clear from equation (13) that $\theta$ is the supply elasticity: as workers' skills become more homogeneous, a given change in $h_{n}^{k} / h_{c}^{k}$ or $w_{n}^{k} / w_{c}^{k}$ affects the occupational choices of more workers, and so solicits a larger response in $L_{n}^{k S} / L_{c}^{k S}$.

We now turn our attention to the demand side. Cost minimization by final goods producers facing technology (4) determines the demand for cognitive and non-cognitive human

\footnotetext{
${ }^{20}$ One could extend the model by having heterogeneous groups of workers (e.g. by gender, education) that draw their talent from different Frechet distributions, and assuming that the number of workers by group is fixed. This setting could generate variation in average education per worker across occupations (e.g. Galle, Rodriguez-Clare, and Yi 2018). However, we do not have occupational employment data by group across countries (see also section 2). As a result, we choose not to complicate the model along this dimension.
} 
capital, implying that the cost share of input $i=c, n$ is given by

$$
s_{i}^{k}=\frac{\left(A_{i}\right)^{\alpha}\left(w_{i}^{k}\right)^{1-\alpha}}{\left(A_{c}\right)^{\alpha}\left(w_{c}^{k}\right)^{1-\alpha}+\left(A_{n}\right)^{\alpha}\left(w_{n}^{k}\right)^{1-\alpha}} .
$$

It follows immediately that the relative demand for non-cognitive human capital is given by

$$
\frac{w_{n}^{k}}{w_{c}^{k}} \frac{L_{n}^{k D}}{L_{c}^{k D}}=\frac{s_{n}^{k}}{s_{c}^{k}} \text { where } \frac{s_{n}^{k}}{s_{c}^{k}}=\frac{\left(A_{n}\right)^{\alpha}\left(w_{n}^{k}\right)^{1-\alpha}}{\left(A_{c}\right)^{\alpha}\left(w_{c}^{k}\right)^{1-\alpha}}
$$

Equation (15) is a standard relative demand equation where the demand elasticity is given by $\alpha$.

Combining the supply and demand side of the economy, we obtain

$$
L_{i}^{k D}=L_{i}^{k S}, i=n, c
$$

We are now in a position to define the equilibrium of our model.

Definition 1 An equilibrium to our model is a set of factor prices $w_{c}^{k}$ and $w_{n}^{k}$ that imply quantities of factors supplied, given by (13), and factors demanded, given by (15). These quantities clear domestic factor markets, given by (16), in conjunction with (11).

\subsection{Output per Worker, HCQI and Output TFP}

We now clarify the connections between $h_{c}^{k}$ and $h_{n}^{k}$ and income differences across countries. We derive an analytical expression that decomposes the differences in output per worker into a component that reflects differences in human-capital productivities, and another that reflects differences in output TFP. To do so, we use equations (8) and (13)-(16) to solve for relative wages:

$$
\frac{w_{n}^{k}}{w_{c}^{k}}=\left[\frac{T_{c}}{T_{n}}\left(\frac{h_{c}^{k}}{h_{n}^{k}}\right)^{\theta}\left(\frac{A_{n}}{A_{c}}\right)^{\alpha}\right]^{\frac{1}{\phi}}, \phi \equiv \theta+\alpha-1>0 .
$$

We then define a base country 0 against which any particular country can be compared. We show that (Theory Appendix 4):

Proposition 1 Output per worker in country $k$ relative to the base country 0 can be decomposed into the ratio of output TFP and HCQI; i.e.

$$
\frac{Y^{k} / L^{k}}{Y^{0} / L^{0}}=\left[\frac{\Theta^{k}}{\Theta^{0}} \Omega^{k}\right]^{\frac{1}{1-\eta}}
$$


where $H C Q I$ is related to the ratios of cognitive and non-cognitive productivities and the occupation employment shares of country 0 :

$$
\Omega^{k} \equiv\left(p_{c}^{0}\left(\frac{h_{c}^{k}}{h_{c}^{0}}\right)^{\frac{\theta(\alpha-1)}{\phi}}+p_{n}^{0}\left(\frac{h_{n}^{k}}{h_{n}^{0}}\right)^{\frac{\theta(\alpha-1)}{\phi}}\right)^{\frac{\phi}{\theta(\alpha-1)}}
$$

Equation (18) says that relative to country 0, country $k$ may have high output per worker for two reasons: one, it may produce the final good more efficiently (i.e. $\Theta^{k} / \Theta^{0}$ is high); and two, it may produce human capital more efficiently (i.e. $\Omega^{k}$ is high). Equation (19) says that country $k$ 's HCQI (relative to country 0 ), $\Omega^{k}$, is a weighted power mean of the ratios of cognitive and non-cognitive productivities, with the weights being the occupational employment shares of the base country 0. This index summarizes the multi-dimensional differences in cognitive and non-cognitive productivities into a single numerical value. Unlike $L_{c}^{k S}$ and $L_{n}^{k S}$, the aggregate quantities of country $k$ 's human capital (in efficiency equivalent units), HCQI is a relative metric, and captures the overall quality of country $k$ 's humancapital production relative to country 0 .

Because the powers in $\Omega^{k}$ are determined by the demand and supply elasticities, $\theta$ and $\alpha$, they play important roles in determining how HCQI relates to cognitive and non-cognitive productivities, $h_{c}^{k}$ and $h_{n}^{k}$. As both $\theta, \alpha \rightarrow \infty, \Omega^{k}$ goes to the maximum of $h_{c}^{k}$ and $h_{n}^{k}$. This is intuitive, as workers become equally capable at both perfectly substitutable tasks. In this case, being strong in producing one type of human capital but weak in producing the other type has few consequences for a country's well-being. As $\alpha \rightarrow-\infty$, however, the aggregate production function becomes Leontief, $\Omega^{k}$ goes to the minimum of $h_{c}^{k}$ and $h_{n}^{k}$, and excelling along a single dimension in human-capital production does little good for national well-being. For the more empirically relevant case found in our data (see below), $\Omega^{k}$ is reasonably well approximated as a geometric mean, where the relative importance of cognitive and non-cognitive productivities is determined by the occupational shares. In this case, both cognitive and non-cognitive productivities are important, and so a country with high productivity along one dimension but low productivity along the other tends to have low HCQI. ${ }^{21}$ We will further illustrate this intuition in section 6 , by drawing a curve along which $\Omega^{k}$ stays constant. We call this the iso-HCQI curve. We will also examine the expressions for HCQI under more general settings in sections 7 and 8, and compare them with equation (19).

We now compare equation (19) with the literature. Caselli and Coleman (2006), Jones (2014) and Malmberg (2017) consider aggregation functions of human capital, where workers

\footnotetext{
${ }^{21}$ Note that as $\alpha$ becomes smaller (i.e. cognitive and non-cognitive human capital become less substitutable in aggregate production), equation (19) assigns a bigger penalty for given imbalances in cognitive and noncognitive productivities.
} 
with different schooling years are imperfect substitutes. These studies abstract away from the production of human capital, and so the results depend on the substitution elasticities of the aggregation function. We focus on human-capital production, and so in (19), HCQI depends on both $\alpha$, the substitution elasticity in aggregate production, and $\theta$, which is like a substitution elasticity in human-capital production. On the other hand, we abstract away from imperfect substitutability within a given type of human capital; e.g. we compute the aggregate supply (in efficiency equivalent units) by summing across workers in equation $(11) .^{22}$

\section{Cognitive and Non-cognitive Productivities: Quan- tification}

In the previous section, we have shown that HCQI depends on non-cognitive and cognitive productivities, $h_{n}^{k}$ and $h_{c}^{k}$. In this section, we show how our model allows us to use data to recover their values, in preparation for quantification in the next section. These steps clarify the intuition for the way we make cross-country comparisons for non-cognitive human capital. They also highlight how our model, where human capital is multi-dimensional, differs from previous studies on human-capital production, which have a single type of human capital.

\subsection{Comparative Advantage and $h_{n}^{k}$}

We begin by backing out a country's comparative advantage in human capital production. Rearranging equation (8), we obtain

$$
\frac{h_{c}^{k}}{h_{n}^{k}}=\left(\frac{p_{c}^{k} / T_{c}}{p_{n}^{k} / T_{n}}\right)^{\frac{1}{\theta}} \frac{w_{n}^{k}}{w_{c}^{k}} .
$$

Intuitively, if a large fraction of the population is employed in cognitive occupations despite a low relative wage in that occupation, it must be that accumulating cognitive human capital is relatively easy. We plug the expression for relative wage, (17), into the expression above, and then divide country $k$ 's expression relative to a base country 0 . These steps yield

$$
\frac{h_{c}^{k} / h_{n}^{k}}{h_{c}^{0} / h_{n}^{0}}=\left(\frac{p_{c}^{k} / p_{n}^{k}}{p_{c}^{0} / p_{n}^{0}}\right)^{\frac{\phi}{\theta(\alpha-1)}}, \phi \equiv \theta+\alpha-1>0 .
$$

\footnotetext{
${ }^{22}$ Conceptually, we can think about embedding this literature in our framework by replacing $L_{c}^{k D}$ and $L_{n}^{k D}$ in equation (4) with, say, CES aggregates of workers with different schooling years. However, we have data for employment by occupation, not by occupation by education. In addition, in our sample of mostly high-income countries, illiteracy is uncommon (see also section 2 and note 29 ).
} 
Equation (20) has the flavor of revealed comparative advantage: we can back out a country's comparative advantage for cognitive human capital, $h_{c}^{k} / h_{n}^{k}$, using the data and parameter values on the right-hand side of (20). This term captures the effects of the endogenous choices of workers and the optimal hiring decisions of the final goods producers. If we observe, in the data, that many have chosen the cognitive occupation in country $k$, we can infer that country $k$ has a strong comparative advantage for cognitive human capital.

Equation (20) also delivers the values of non-cognitive productivity, $h_{n}^{k}$, if we have the values of cognitive productivity, $h_{c}^{k}$. These $h_{n}^{k}$ values compare how well different countries produce non-cognitive human capital, and provide a solution to a major challenge for the literature on non-cognitive human capital. To put our results into the context of this literature, we note that while there are direct measures to compare cognitive human capital across countries, such as test score, no such measure is available for non-cognitive human capital. Our discussions in Introduction suggest that it could be difficult to come up with such a measure. ${ }^{23}$ Equation (20) says that even without such a measure, we can still make cross-country comparisons for the non-cognitive dimension, by leaning on the measure we have for the cognitive dimension, and revealed comparative advantage. ${ }^{24}$

Finally, to show the importance of the key demand-side elasticity, $\alpha$, we re-write (20) as

$$
\frac{p_{c}^{k} / p_{n}^{k}}{p_{c}^{0} / p_{n}^{0}}=\left(\frac{h_{c}^{k} / h_{n}^{k}}{h_{c}^{0} / h_{n}^{0}}\right)^{\frac{\theta(\alpha-1)}{\phi}} .
$$

Suppose $h_{c}^{k} / h_{n}^{k}$ increases; i.e. country $k$ has a stronger comparative advantage in producing cognitive human capital. By equation (8), this has a direct effect on the relative employment share of cognitive occupations, $p_{c}^{k} / p_{n}^{k}$, as well as an indirect effect on it, through the movement of the relative return to cognitive human capital, $w_{c}^{k} / w_{n}^{k}$. Equation (20) says that the net effect depends on $\alpha$. If $\alpha>1$, demand is elastic, and so the movement in the relative return is small, and the direct effect dominates. Therefore, a larger relative employment share of cognitive occupations reflects a greater comparative advantage for cognitive human capital. When $\alpha \leq 1$, however, this result does not hold. We show, in section 5 below, that data indicates $\alpha>1$.

\footnotetext{
${ }^{23}$ See also Deming (2017b).

${ }^{24}$ We have used U.S. data to classify occupations and applied this classification across countries, with the implicit assumption that occupational rankings in terms of the importance of leadership are similar across countries. We do so because for most countries, occupation-characteristic data is not available. As a result, many studies use the same approach as we do, drawing on the U.S. O*NET (e.g., Hummels, Munch and Xiang 2018 provide a recent survey). We also provide some empirical evidence for this assumption in section 8.3 .
} 


\subsection{Absolute Advantage and $h_{c}^{k}$}

We now turn to backing out a country's absolute advantage in producing human capital from data. Because a large literature has argued that a country's average score on international exams, such as PISA, is a quality-adjusted measure of this country's cognitive human capital, we assume that country $k$ 's average PISA score, $S^{k}$, is informative about its average cognitive human capital, $L_{c}^{k S} / L^{k}$, where $L_{c}^{k S}$ is given by $(11) ;{ }^{25}$ i.e. for some positive constant $b$, we assume that

$$
S^{k}=b \frac{L_{c}^{k S}}{L^{k}}
$$

We then start from assumption (21), and obtain $k$ 's cognitive productivity by appropriately adjusting $S^{k}$ for resources expenditures and occupational choices. To do so, we combine (21) with equations (8), (10), (11) and (12), to obtain the following expression for country $k$ 's test score relative to a base country 0 (Theory Appendix 5):

$$
\frac{S^{k}}{S^{0}}=\left(\frac{E^{k}}{E^{0}}\right)^{\eta}\left(\frac{p_{c}^{k}}{p_{c}^{0}}\right)^{1-\frac{1}{\theta}}\left(\frac{h_{c}^{k}}{h_{c}^{0}}\right)
$$

As expression (22) makes clear, a good showing on international tests can happen for multiple reasons. First, a high test score could be obtained by a high level of spending on education per capita, $E^{k}$. The effect of $E^{k}$ on cognitive human capital, and so test score, is raised to the power of $\eta$, because the production technology of human capital, (2), is subject to diminishing returns.

The second term in (22) captures the effects of incentives and selection, and they arise in general equilibrium because heterogeneous individuals make optimal choices for human capital investment. To see these effects, suppose that many choose the cognitive occupation in country $k$; i.e. $p_{c}^{k}$ is high. This means that the cognitive occupation is an attractive career choice, and so individuals have strong incentives to accumulate cognitive human capital. This incentive effect implies high average test score for country $k$, and its magnitude is raised to the power of 1 .

On the other hand, workers are heterogeneous, and so a high $p_{c}^{k}$ implies that many individuals with low innate cognitive abilities have self-selected into the cognitive occupation. Their presence tends to lower the average cognitive human capital, and so the test score. The magnitude of this selection effect is $p_{c}^{k}$ raised to the power of $-1 / \theta$. If $\theta$ is large, the distribution of innate abilities becomes more compressed. This means less individual heterogeneity and so the selection effect is weaker. Note that, because $\theta>1$, the incentive effect always dominates. We allow the data to steer us to the most appropriate value for $\theta$, and it will turn out that the value does indeed exceed one.

\footnotetext{
${ }^{25}$ One may worry how the specific scale of PISA scores may affect our results. We address this issue in sub-section 8.1.
} 
Finally, cognitive productivity, $h_{c}^{k}$, soaks up all the other reasons why the test score is high for country $k$, net of the effects of resources, and incentives minus selection. An important implication of equation (22) is that, in order to isolate $h_{c}^{k}$, one has to adjust test scores for the convoluting factors of educational expenditures and occupational employment shares.

\subsection{Human Capital: Multiple Types, versus A Single Type}

In this sub-section we compare our framework with a model where human capital is of a single type. We begin by setting $p_{n}^{k}=0$ and $p_{c}^{k}=1$ in our model. Then equations (18) and (19) imply

$$
\frac{Y^{k} / L^{k}}{Y^{0} / L^{0}}=\left[\frac{\Theta^{k}}{\Theta^{0}} \Omega^{k}\right]^{\frac{1}{1-\eta}}, \Omega^{k}=\frac{h_{c}^{k}}{h_{c}^{0}}
$$

while (22) and (21) imply

$$
\frac{S^{k}}{S^{0}}=\left(\frac{\Theta^{k}}{\Theta^{0}}\right)^{\frac{\eta}{1-\eta}}\left(\Omega^{k}\right)^{\frac{1}{1-\eta}}
$$

Equations (23) and (24) show that holding $\Theta^{k}$ fixed, a country that produces cognitive human capital well (high $h_{c}^{k}$ ) also has high test score and high output per worker. In other words, the distinction between the quantity of cognitive human capital (in efficiency equivalent units), $S^{k}$, and its TFP, $h_{c}^{k}$, is not important, and there is a monotonic relationship between this quantity and output per worker. These results are intuitive. In this onedimensional world, there is no comparative advantage; thus only absolute advantage matters, and HCQI, $\Omega^{k}$, is the same as cognitive productivity, $h_{c}^{k}$.

Equations (23) and (24) also show that we are using two parameters, $\Theta^{k}$ and $h_{c}^{k}$, for absolute advantage, and so one is redundant. Setting $h_{c}^{k}=h_{c}^{0}$ for all $k$, we obtain

$$
\frac{Y^{k} / L^{k}}{Y^{0} / L^{0}}=\left[\frac{\Theta^{k}}{\Theta^{0}}\right]^{\frac{1}{1-\eta}}, \frac{S^{k}}{S^{0}}=\left(\frac{\Theta^{k}}{\Theta^{0}}\right)^{\frac{\eta}{1-\eta}}
$$

This expression says that a country with high output TFP (high $\Theta^{k}$ ) has a large quantity of cognitive human capital (high $S^{k}$ ) and so high output per worker. ${ }^{26}$ In addition, a given difference in output TFP can be amplified through human-capital production. ${ }^{27}$ This explains why in the human-capital production literature, the focus is on the mechanisms that affect the degree of amplification, such as demographics, the complementarity between physical capital and human capital, and whether human capital is produced using time, physical

\footnotetext{
${ }^{26}$ Erosa et al (2010) and Manuelli and Seshadri (2014) measure the quantity of human capital (in efficiency equivalent units) using spending, while Cubas et al (2016) use average PISA score.

${ }^{27}$ Findlay and Kierzkowski (1983) does not have amplification, because the input to human-capital production is not produced by human capital, but has an exogenously given quantity, like an endowment.
} 
goods, or services. The main question there is the relative contribution of human capital versus output TFP in explaining cross-country differences in output per worker. ${ }^{28}$

In comparison, we have taken a different path, and abstracted away from many amplification mechanisms. In our framework, a country with a high test score may not produce cognitive human capital well, by (22); i.e. we need to distinguish between the quantity of cognitive human capital and its TFP. More importantly, a country with a high test score, or a large quantity of cognitive human capital, may not have high output per worker, by equations (18) and (19); i.e. the non-cognitive dimension is potentially important. As a result, we need to derive the theoretical expression for HCQI and compute this index using data.

These discussions do not suggest that we have a better model for human-capital production. After all, both the magnification mechanisms and the multi-dimensionality of human capital can be important. The point is that our model has a very different focus as, and so is complementary to, the existing literature on human-capital production. In addition, the building blocks of our framework, including (22) and (21), are compatible with this literature.

So far we have focused on how our framework makes a difference, in theory. In the data, how do countries' PISA scores differ from their cognitive productivities? How do countries compare in terms of their TFP's for non-cognitive human capital? Does this second dimension matter? How does HCQI compare with test score, as a measure for the overall quality of human capital? We answer these questions by quantifying our model.

\section{$5 \quad$ Data and Parameter Values}

Our model is based on the premise that both non-cognitive and cognitive occupations require human capital, and one may wonder whether there are occupations in our data for which human capital is not relevant. Columns 4 and 5 of Table 1 show that the coefficient estimate of test score remains positive and significant after we control for the college dummy. Kuhn and Weinberger (2005) report that the marginal effect of leadership skills is as strong for low-education individuals as for high-education ones. When we tabulate the distribution of average schooling years across occupations using the 2000 US Census, we find that this distribution is compressed in the left; e.g. the median is 12.8 years while the 5 th percentile is 10.9 years. These results are intuitive, because the U.S. is a high-income country, where illiteracy,

\footnotetext{
${ }^{28} \mathrm{~A}$ key parameter in these studies is the amplification elasticity. It is between 2 and 3 in Erosa et al. (2010) and Cubas et al. (2016), and exceeds 9 in Manuelli and Seshadri (2014). In comparison, our amplification elasticity, $1 /(1-\eta)$, is close to 1 , given our $\eta$ estimate of 0.1255 (see the next section).
} 
subsistence farming and the informal sector are not salient features of the economy. ${ }^{29} \mathrm{We}$ therefore use the 28 high-income countries as our main sample. These high-income countries account for $42.94 \%$ of world GDP in 2000 .

The upper panel of Table 2 reports the summary statistics for our main sample, and Table 3 lists the countries and years in this sample. We already discussed the occupation employment shares, $p_{c}^{k}$ and $p_{n}^{k}$, in section 2. For test score, $S^{k}$, we obtain mean PISA scores in reading, math and science from the official PISA website. ${ }^{30} 31$ For aggregate output, $Y^{k}$, we use labor income, or compensation of employees from NIPA (National Income and Product Account), since we do not have physical capital in our model. ${ }^{32}$ We obtain the ratios of private plus public expenditures on education to GDP in 2004 from the UNESCO Global Education Digest of 2007. The lower panel reports the same statistics for our expanded sample, which is our main sample plus the middle-income countries of Bulgaria, Estonia, Latvia, Lithuania, Romania and Thailand. Note that all our data come from public sources.

In the rest of this section, we use these data and our model to extract the values of the elasticities, $\theta, \eta$, and $\alpha$, and final-good TFP, $\Theta^{k}$, and the TFPs of human capital production, $h_{n}^{k}$ and $h_{c}^{k}$.

\subsection{Elasticity of Human Capital Production, $\eta$}

We begin with $\eta$, the elasticity of human capital output with respect to resources input. It is straightforward to show that

\footnotetext{
${ }^{29}$ Caselli and Coleman (2006) make a similar point, classifying primary-school completion as skilled labor in the benchmark specification.

${ }^{30}$ We use PISA scores because they are widely reported in the media, and have influenced education policies in many countries. In addition, PISA samples students in a nationally representative way, covers many countries, and controls qualities of the final data (e.g. the 2000 UK scores and 2006 US reading scores are dropped because of quality issues). Finally, while PISA scores are for high-school students, they are highly correlated with the scores of adult tests (e.g. Hanushek and Zhang 2009). Compared with PISA, adult tests cover substantially fewer countries (they would cut our sample size by at least 25\%) and also have lower response rates (e.g. Brown et al. 2007). See also Data Appendix 4.

${ }^{31}$ When PISA first started in 2000, only the reading test was administered, and only a small set of countries participated. In order to obtain PISA scores in all three subjects for every country in our sample, we calculate simple averages over time by country by subject, using all years of available data; e.g. Germany's PISA math score is the simple average of 03, 06, 09 and 2012, U.K.'s reading score the average of 06, 09 and 2012, etc. In Data Appendix 4 we show that PISA scores do not have large over-time variation.

${ }^{32}$ We experimented with stripping capital from GDP, obtained from PWT (Penn World Tables), by assuming a Cobb-Douglas production function and using the parameter values from the macro literature (e.g. Klenow and Rodriguez-Clare 1997). The aggregate output of this second approach has a correlation of 0.9994 with our main output variable.
} 
Proposition 2 Country $k$ spends fraction $\eta$ of its aggregate output on education; i.e.

$$
E^{k} L^{k}=\eta Y^{k}
$$

Proof. By equations (9) and (10), $w_{i}^{k} L_{i}^{k}=L^{k} p_{i}^{k} E^{k} / \eta$, and so $\eta\left(\sum_{i} w_{i}^{k} L_{i}^{k}\right)=L^{k} E^{k}\left(\sum_{i} p_{i}^{k}\right)=$ $E^{k} L^{k}$. In our model aggregate output equals aggregate income, and so $\eta\left(\sum_{i} w_{i}^{k} L_{i}^{k}\right)=\eta Y^{k}$.

By equation (25), $\eta$ is the ratio of aggregate educational spending, $E^{k} L^{k}$, to aggregate output, $Y_{k}$. Therefore, we set its value to match the mean share of public plus private educational expenditure in output, 0.1255 (see Table 2). Note that the standard deviation of this share (across countries) is low, at 0.0194. In addition, the mean remains almost unchanged at 0.1228 in the expanded sample.

Next, to obtain the values of $\theta$ and $\alpha$, we can either follow the common practice of using the estimates from the literature, or do our own calibration. Although these two approaches yield very similar results, we develop and discuss the steps of our calibration in the next two sub-sections, because these steps produce falsifiable predictions that show whether or not our model fits the data.

\subsection{Supply Elasticity, $\theta$, and Cognitive Productivity, $h_{c}^{k}$}

We start with $\theta$, which measures the dispersion of innate abilities across workers and also governs the elasticity of the aggregate supplies of human capital. Using the results of the previous proposition and equation (22), we obtain

$$
\ln \left(\frac{S^{k}}{\left(Y^{k} / L^{k}\right)^{\eta}}\right)=D+\left(1-\frac{1}{\theta}\right) \ln p_{c}^{k}+\ln h_{c}^{k}
$$

where $D$ is a constant. ${ }^{33}$ Equation (26) is useful for several reasons.

First, it is a falsifiable prediction of our model. It instructs us to construct novel variables and to look for novel correlation patterns that previous research has not examined. We follow these instructions in Figure 2. The vertical axis is log PISA math score, normalized by the logarithm of output per worker raised to the power of $\eta$. The horizontal axis is $\log$ cognitive employment share. We weigh the data in the scatterplot using aggregate output. ${ }^{34}$ Figure $2 \mathrm{a}(2 \mathrm{~b})$ shows the main (expanded) sample. Figure 2 shows that, consistent with (26), the countries in which workers are clustered in cognitive occupations are the countries that score well on international tests (normalized by resources inputs), which can measure primarily cognitive achievement.

\footnotetext{
${ }^{33}$ Relative to (21), (26) has output per worker rather than educational expenditure per worker, because we have more data points on output per worker.

${ }^{34}$ The countries in our sample vary a lot in size (e.g. Switzerland, Germany, and the United States.)
} 
Second, recall that our occupation-employment data is based on our occupation classification. In section 2, we have motivated this classification using micro data from the U.S. The correlation pattern, proposed in equation (26) and validated in Figure 2, shows that our classification is also consistent with cross-country macro data.

Third, equation (26) provides the target for our $\theta$ value. Figure 2a plots the best-fit line, and it has $R^{2}=0.175$ and a slope coefficient of 0.493 . We choose the value of $\theta$ to match this slope coefficient, and obtain $\theta=1.973$ (since the slope coefficient is $1-\frac{1}{\theta}$ ). ${ }^{35}$ This estimate is consistent with our assumption in section 3 that $\theta>1$.

One may wonder whether cognitive employment share is correlated with cognitive productivity in (26), and whether this correlation is an issue for our $\theta$ value. We use equations (8) and (17) to show that

$$
p_{c}^{k}=\frac{1}{1+\left(\frac{A_{n}}{A_{c}}\right)^{\frac{\alpha \theta}{\phi}}\left(\frac{T_{n}}{T_{c}}\left(\frac{h_{n}^{k}}{h_{c}^{k}}\right)^{\theta}\right)^{\frac{\alpha-1}{\phi}}}
$$

This expression clarifies that cognitive employment share is determined by comparative advantage, $h_{n}^{k} / h_{c}^{k}$. Therefore, cognitive employment share is uncorrelated with cognitive productivity if cognitive productivity, a measure of absolute advantage, is uncorrelated with comparative advantage. We look at alternative specifications below, in Table 4, and alternative $\theta$ values in Table 5 . We also compare our $\theta$ values with the literature.

The upper panel of Table 4 shows the results for our main sample. All the columns of Table 4 use PISA math score, and have aggregate output as weights. ${ }^{36}$ Column (2) corresponds to the best-fit line in Figure 2a. In column (1) we add Australia and New Zealand but dummy them out, ${ }^{37}$ and obtain very similar results. This is our benchmark specification, and we recap its $\theta$ value in row (1) of Table 5 . In column (3) of Table 4 we use the characteristic of guiding and directing subordinates to classify occupations. The slope coefficient becomes larger, implying a larger $\theta$, which we list in row (3) of Table 5 . The $R^{2}$ is also higher. Column (4) of Table 4 uses the characteristic of enterprising skills. The coefficient is positive but not significant, and this pattern echoes column (6) of Table 1 . The lower panel of Table 4 shows the results for the expanded sample, and they are similar to the results in the upper panel. We list the $\theta$ value for column (1) of the lower panel of Table 4 in row (4) of Table 5.

\footnotetext{
${ }^{35}$ Card and Lemieux (2001) infer the substitution elasticity across different types of workers by regressing relative wages on relative supply (plus other controls). This approach has a similar flavor to our approach.

${ }^{36}$ We have experimented with different weights and the scores of other PISA subjects, and obtained similar results. See Data Appendix 5.

${ }^{37}$ In the raw data of Australia and New Zealand, the occupation classification codes are their own national codes rather than ISCO 88. See also note 14.
} 
One may be concerned that our $\theta$ estimates come from a single cross-section of 30 or so countries. We compare them with the estimates from the literature. Our benchmark value is $\theta=1.973$. Hsieh et al (2018)'s model also features a Frechet distribution of innate abilities, but for identification they use worker-level data and explore wage dispersion within occupations and labor-force participation from the U.S.; i.e. their data and identification strategy are completely different from ours. Despite such differences, Hsieh et al (2018) obtain $\theta=2 .^{38}$ In other words, we will obtain similar results if we use the $\theta$ estimates from the literature.

We now plug $\theta=1.973$ into equation (26) to compute cognitive productivities, $h_{c}^{k}{ }^{39}$ These values are relative, and so we normalize the U.S. value to 1 . Since we have gone through several specifications, we compare their $h_{c}^{k}$ values with the benchmark values in Table 5. They are all similar to the benchmark values. We summarize the way we have obtained $\eta, \theta$ and $h_{c}^{k}$ in Table 6 . Table 6 also lists the literature's estimates for $\theta$.

Finally, we address the issue of test score scale in section 8 , and discuss our $h_{c}^{k}$ values in section 6 . We now move on to $\alpha$, the substitution elasticity on the demand side.

\subsection{Demand Elasticity, $\alpha$, Output TFP, $\Theta^{k}$, and Non-cognitive Productivity, $h_{n}^{k}$}

We combine equations (4), (13), (15), (16) and (21) to obtain (Theory Appendix 6)

$$
\log \left(\frac{Y^{k}}{S^{k} L^{k}}\right)=F+\frac{\alpha}{\alpha-1} \log \left(1+\frac{p_{n}^{k}}{p_{c}^{k}}\right)+\log \Theta^{k}
$$

where the constant $F$ has no cross-country variation.

Equation (27) is an input-output relationship. The output is $Y^{k}$, and there are two inputs. The first is the quantity of cognitive human capital (in efficiency equivalent units), represented by $L^{k} S^{k}$, since test score, $S^{k}$, represents average cognitive human capital by equation (21). The second input is the relative quantity of non-cognitive human capital used in production, and it is a monotonic function of $p_{n}^{k} / p_{c}^{k}$. Therefore, equation (27) shows how aggregate output, normalized by the quantity of cognitive human capital, varies with the relative quantity of non-cognitive human capital.

For our model, (27) is another falsifiable prediction that can be taken to the data. It instructs us to use the average test score as one input and the ratio of employment shares as the relative quantity of another input. These are novel ways to measure the quantities of

\footnotetext{
${ }^{38}$ The range of $\theta$ values is 1.5 to 2.5 in Hsieh et al (2018), 1.78 to 2.62 in Burnstein et al. (2016), and 1.48 to 2.5 in Lee (2016). Lagakos and Waugh (2013), whose model has industries and not occupations, obtain $\theta=2.7$ for the non-agricultural sector. In comparison, our range is 1.746 to 3.014 (see Table 5).

${ }^{39} \mathrm{By}$ attributing the residual in equation $(26)$ to $\ln h_{c}^{k}$, we follow the common approach in the literature that output TFP is the residual of the aggregate production function.
} 
human capital that previous research has not considered. In addition, equation (27) provides the target for our value of $\alpha$.

Table 7 shows the results of fitting our data using (27). The structure of Table 7 is similar to Table 4, where all columns use PISA math score and aggregate output as weights. ${ }^{40}$ Column (1) is our benchmark specification. The coefficient of $\log \left(1+\frac{p_{n}^{k}}{p_{c}^{k}}\right)$ is positive and significant, and implies $\alpha=1.676$. This estimate for $\alpha$ provides an additional validation of our model, which, as we discussed in section 3, requires $\alpha>1$. Column (2) drops Australia and New Zealand, and column (3) uses guiding-and-directing-subordinates to classify occupations. The results are similar to column (1). Column (4) uses enterprising skills, and obtains a positive, but not significant, coefficient of $\log \left(1+\frac{p_{n}^{k}}{p_{c}^{k}}\right)$, echoing Tables 1 and 4 . The lower panel shows the results for the expanded sample, and they are similar to the upper panel. Table 5 lists the $\alpha$ values of several of the specifications we have gone through, and show that they are similar to the benchmark value of 1.676 .

We now compare our $\alpha$ estimates with the literature. Burnstein et al. (2016) feature a CES aggregate production function, like us, but for identification they use cross-section and over-time variations in occupational wages and employment in micro data for the U.S. Although Burnstein et al. (2016)'s data and identification strategy are completely different from ours, they obtain $\alpha=1.78$. This means that we will obtain similar results if we use the $\alpha$ estimates from the literature.

We then plug $\alpha=1.676$ into equation (27) to compute the output TFP, $\Theta^{k}$, normalizing the U.S. value to 1 . We check the correlation coefficients between our output TFP estimates and those reported in the literature. They are all positive and significant, ranging from 0.447 (Klenow and Rodriguez-Clare 1997) to 0.669 (PWT 8.0), and provide an external validation for our approach (see Data Appendix 6 for more details).

Finally, we use the values of $\theta$ and $\alpha$ and equation (20) to compute the comparative advantage for cognitive human capital, $h_{c}^{k} / h_{n}^{k}$. We combine these values with $h_{c}^{k}$ to back out non-cognitive productivity, $h_{n}^{k}$. The $h_{n}^{k}$ values are again relative, and we normalize the U.S. value to 1 . Table 5 shows that the $h_{n}^{k}$ values of our alternative specifications are similar to the benchmark values. Table 6 summarizes the way we have obtained $\alpha, \Theta^{k}$, and $h_{n}^{k}$, and also lists the $\alpha$ estimates from the literature.

\section{Results}

In this section we present the values of cognitive productivities, non-cognitive productivities, and HCQI. We draw out their economic significance, and then discuss their potential implications for policy.

\footnotetext{
${ }^{40}$ See Data Appendix 5 for alternative weights and subjects, with similar results.
} 


\subsection{Cognitive Productivity}

Figure 3 plots the countries' rankings in $h_{c}^{k}$ against their rankings in PISA math score, and Table 3 lists these rankings by country. These two rankings are positively correlated (0.561), since both test score and cognitive productivity measure the cognitive dimension. However, Figure 3 shows that they are quite different for many countries. We highlight these differences using the 45 degree line. These differences arise because in our model, human capital is multi-dimensional; test score is the outcome along the cognitive dimension, and so distinct from the underlying TFP of this dimension. Equation (26) shows two sources of their differences.

The first is resources, $\left(Y^{k} / L^{k}\right)^{\eta}$. Other things equal, a country with more resources inputs is expected to produce better outcome. To see this, consider Poland, Czech Republic, Hungary and Slovakia. They have decent PISA scores, ranked outside of top 10. However, our model says that this outcome should be viewed in the context of low output per worker in these countries, and so limited resources for human capital production. Therefore, their cognitive productivities are better than their test scores suggest.

The second is incentives (minus selection), $\left(1-\frac{1}{\theta}\right) \ln p_{c}^{k}$. The country where individuals are strongly incentivized to learn cognitive skills will perform well in international tests. To see this, consider Hong Kong, South Korea and Switzerland. They are superstars in PISA scores, all ranked within top 5. However, our model says that this outcome should be viewed in the context of high cognitive employment shares and so strong incentives to accumulate cognitive human capital. Therefore, their cognitive productivities are not as good as their test scores suggest.

Finally, we look at the U.S. First, the U.S. has very high output per worker. The abundance of resources makes the low U.S. PISA scores even harder to justify. Second, the employment share of cognitive occupations is relatively low in the U.S., implying weak incentives to accumulate cognitive human capital. The effects of resources and incentives offset each other, leaving the U.S. ranking in cognitive productivities very close to its ranking in PISA scores, near the bottom in our set of 28 countries. In our Introduction, we discussed the worries and concerns about the quality of the U.S. educational institution. Figure 3

quantifies these concerns and shows that they are well justified, when we look at the cognitive dimension. We now turn to the non-cognitive dimension.

\subsection{Non-cognitive Productivity}

Figure 4 plots the countries' rankings in $h_{n}^{k}$ against their rankings in PISA math score, and Table 3 lists the rankings by country. Figure 4 clearly shows that the PISA-math rankings are simply not informative about non-cognitive productivity rankings (correlation $=0.029$ 
with $\mathrm{p}$-value $=0.884$ ). Thus non-cognitive productivities open up a novel dimension for cross-country comparison, which is hidden from PISA scores. This new dimension gives us new perspectives.

First, Figure 4 shows that PISA scores overstate the proficiency of South Korea, Hong Kong and Switzerland in producing non-cognitive human capital. While these countries are top performers in PISA score, they are at the bottom in terms of non-cognitive productivity, for two reasons. First, they have decent, but not stellar, cognitive productivities (see Figure 3). In addition, in these countries, many choose the cognitive occupations, implying weak comparative advantages for non-cognitive human capital, by equation (20). In our Introduction, we discussed the concerns in S. Korea and many East Asian countries that the educational systems emphasize exams so much that students are unable to develop noncognitive skills. Our results in Figure 4 quantify this issue and suggest that these concerns are well grounded.

Second, Figure 4 shows that PISA scores substantially understate the proficiency of the U.S. and U.K. in fostering non-cognitive human-capital. While both the U.S. and U.K. have low PISA-score rankings, their rankings in non-cognitive productivity are No. 7 and No. 4, respectively. Many in the U.S. have long argued against focusing exclusively on test scores in education. ${ }^{41}$ Figure 4 provides quantifications for this argument, showing that the U.S. is indeed strong along the non-cognitive dimension.

Finally, Figures 3 and 4 show that Finland, Netherlands and Belgium have high rankings in both cognitive and non-cognitive productivity. Intuitively, this is because they have high PISA scores but low cognitive employment shares (relative to the other countries in our sample). This implies that if education-policy makers would like to choose some countries to emulate, Finland, Netherlands and Belgium might be better candidates than, say, South Korea and Hong Kong.

Below we condense the multi-dimensional differences in cognitive and non-cognitive productivities into a single index, HCQI.

\subsection{HCQI}

We compute HCQI, $\Omega^{k}$, using equation (19). Figure 5 plots the value of $h_{c}^{k}$ against the value of $h_{n}^{k}$, and provides a 2-dimensional illustration of the differences in $h_{c}^{k}$ and $h_{n}^{k}$ across our sample countries. It also serves as our canvas for the iso-HCQI curve, the combinations of $h_{c}^{k}$ and $h_{n}^{k}$ that yield a constant level of overall quality of human capital. We draw the iso-HCQI curve through the U.S., our benchmark country with $h_{c}^{U S}=h_{n}^{U S}=1$. This curve

\footnotetext{
${ }^{41}$ For example, the National Education Association states that, in response to NCLB and RTT, "We see schools across America dropping physical education ... dropping music ... dropping their arts programs ... all in pursuit of higher test scores. This is not good education."
} 
illustrates the countries whose HCQI's are similar to the U.S. (e.g. Sweden and Austria), those with higher HCQI's relative to the U.S. (e.g. the U.K. and Finland), and those with lower HCQI's (e.g. Italy and S. Korea). ${ }^{42}$

The curvature and shape of the iso-HCQI curve are determined by equation (19), and they tell us the trade-offs of increasing cognitive productivity for non-cognitive productivity. Intuitively speaking, given the values of $\alpha$ and $\theta$, equation (19) says that both cognitive and non-cognitive productivities are important in overall human-capital quality. We see, in Figure 5, that the countries with high productivity along one dimension but low productivity along the other (e.g. Portugal and Hong Kong) lie below the iso-HCQI curve, meaning that they have lower overall human-capital quality than the U.S. This is because the imbalance of their productivities holds down their HCQI. There is, however, a silver lining: this imbalance would be a useful asset under free trade, as we show in section 7 .

We now spell out the connection between HCQI and output per worker, by implementing the decomposition of equations (18) and (19) in Table 8. Column 1 shows output per capita by country, relative to the United States (i.e. $\frac{Y^{k} / L^{k}}{Y^{0} / L^{0}}$ ). Columns 2 and 3 show, respectively, the contribution of output TFP, $\left[\frac{\Theta^{k}}{\Theta^{0}}\right]^{\frac{1}{1-\eta}}$, and of HCQI, $\left[\Omega^{k}\right]^{\frac{1}{1-\eta}}$. To interpret these results, consider France. The overall quality of France's human capital is low relative to the U.S., the effect of which puts France's output per worker at $91.15 \%$ of the U.S. level (column 3). On top of this, France also has low output TFP relative to the U.S., the effect of which places its output per worker at $80.41 \%$ of the U.S. level (column 2). Aggregating these two effects, France's output per worker is $73.29 \%(=91.15 \%$ x $80.41 \%)$ of the U.S. level (column 1). The decomposition in columns 1-3 is exact for every country, even though column 1 is obtained directly from data while columns 2-3 are calculated using our model parameters.

Column 3 shows that the differences in HCQI across countries have large implications for output per worker. For example, although S. Korea's system of human-capital production delivers high test scores, it puts S. Korea's output per worker at $76.15 \%$ of the U.S. level, other things equal. Finland, on the other hand, has one of the highest HCQI's in our sample, which puts Finland's output per worker at $151.96 \%$ of the U.S. level, ceteris paribus.

We now explore whether the cognitive dimension or the non-cognitive dimension drives the variation in HCQI. We construct the non-cognitive component of HCQI by setting $h_{c}^{k}=1$ for all $k$ in equation (19), ${ }^{43}$ and show, in row (2) of Table 5, that it is highly correlated with HCQI itself (the correlation coefficient is 0.947 ). This means that most of the variation in HCQI is along the non-cognitive dimension, the novel dimension of our analyses.

\footnotetext{
${ }^{42}$ Figure 5 shows our main-sample countries. We show our expanded-sample countries in Figure A3 in the Appendix, and it is similar to Figure 5.

43 "Non-cognitive component" is a slight abuse of terminology, since the functional form of HCQI in (19) does not allow for an exact decomposition into the contributions of $h_{c}^{k}$ and $h_{n}^{k}$.
} 


\subsection{HCQI vs. Test Score}

We now compare HCQI, a quality measure for multiple types of human capital, with relative PISA score, a widely-used quality measure for a single type of human capital.

Columns (1) and (5) of Table 9 show the results of regressing log PISA math on log output per worker. The left (right) panel uses output (labor-force size) as weights, and the upper (lower) panel is for our main sample (expanded sample). PISA score has negative and significant correlation with output per worker in our main sample of high-income countries. This is puzzling, given that relative test score measures the quality of human capital, which is presumably an input in the aggregate production function. With the addition of middleincome countries in the expanded sample, this correlation loses statistical significance. It remains negative under output weight, and turns positive under labor-force-size weight.

In comparison, when we regress log HCQI on log output per worker, we obtain more positive correlation. Columns (2) and (6) of Table 9 use the principal component of leadership characteristics, while columns (3) and (7) use the characteristic of guiding and directing subordinates. For the main sample, where the correlation is negative and significant for test score, it is slightly positive, and insignificant, for HCQI. For the expanded sample, where the correlation is positive and insignificant for test score, it is positive and significant for HCQI, with almost twice the $R^{2}$.

These results are intuitive for our framework. Human capital is multi-dimensional, and test score captures only the cognitive dimension. In comparison, HCQI captures some of the non-cognitive elements that test score has missed. As we show in the previous sub-section, the variation along the non-cognitive dimension is substantial among high-income countries.

These results also provide the first external validation for the values of our non-cognitive productivities and HCQI. This is useful, given that ours is the first to offer a theoretical derivation of HCQI, and to provide cross-country comparisons of non-cognitive human capital and HCQI in the data.

\subsection{Comparative Statics}

In this sub-section we discuss the potential policy implications of our framework, by showing how changes in the human capital productivities, $h_{c}^{k}$ and $h_{n}^{k}$, affect test scores and aggregate output for any country $k$. We assume that there is no change in the labor-force size, $L^{k}$, or output TFP, $\Theta^{k}$.

Let $\widehat{z}$ denote the value of variable $z$ at the subsequent equilibrium relative to its value at the initial equilibrium; i.e. $\widehat{z}=z^{\prime} / z$. Equation (19) simplifies to ${ }^{44}$

\footnotetext{
${ }^{44}$ The base "country 0 " in equation (19) can be interpreted as the initial equilibrium of country $k$ itself.
} 


$$
\widehat{Y^{k}}=\left[p_{c}^{k}\left(\widehat{h_{c}^{k}}\right)^{\frac{\theta(\alpha-1)}{\theta+\alpha-1}}+p_{n}^{k}\left(\widehat{h_{n}^{k}}\right)^{\frac{\theta(\alpha-1)}{\theta+\alpha-1}}\right]^{\frac{\theta+\alpha-1}{\theta(\alpha-1)} \frac{1}{1-\eta}}
$$

Equation (28) says that, because $h_{c}^{k}$ and $h_{n}^{k}$ affect aggregate output through HCQI, the output change depends on the weighted power mean of the changes in $h_{c}^{k}$ and $h_{n}^{k}$, with occupation employment shares as weights.

On the other hand, for small changes in test score, we have ${ }^{45}$

$$
(1-\eta) d \ln S^{k}=\left(1+B p_{c}^{k}\right) d \ln h_{c}^{k}-\left(B p_{n}^{k}\right) d \ln h_{n}^{k}, B=\frac{(\theta-1)(\alpha-1)-\alpha \eta}{\theta+\alpha-1},
$$

where $B=0.169$ according to our parameter values. Equation (29) says that an increase in test score, $S^{k}$, can be achieved by either an increase in cognitive productivity, $h_{c}^{k}$, and/or a reduction in non-cognitive productivity, $h_{n}^{k}$. The latter works because an educational institution with a very low level of non-cognitive productivity simply pushes most people away from choosing the non-cognitive occupation, by equation (8). This creates very strong incentives to accumulate cognitive human capital, showing up as an increase in test score. As a result, a rise in test score may result from a higher HCQI along the cognitive dimension, or a worse one along the non-cognitive dimension.

Equations (28) and (29) suggest that in our framework, aggregate output and test score may move in opposite directions. To illustrate this point, suppose the U.S. implements an education policy that places less emphasis on test scores and more emphasis on non-cognitive skills. Assume that this policy increases U.S. non-cognitive productivity by $1 \%$, and leave her cognitive productivity unchanged. Looking at test score, we might conclude that this policy is unsuccessful, because by equation (29), U.S. test score would drop, slightly, by $0.05 \%$. Looking at output, however, we would likely draw the opposite conclusion, because by equation (28), U.S. aggregate output would increase by $0.29 \%$.

This result is intuitive for our model. There are multiple types of human capital, and heterogeneous individuals respond to policies by changing the types of human capital they invest in. Both absolute and comparative advantages matter for HCQI and aggregate output. In comparison, in a model with a single type of human capital, there will be a monotonic relationship between test score and output, because only absolute advantage matters (see equations (23) and (24)).

This result could also be relevant for several early childhood intervention programs in the U.S. A large body of work shows that these programs tend to have little long-term effects on program participants' test scores, but positive effects on their adult outcome, such as higher wages, and lower probabilities of poverty and crime (see the Introduction). This body of work also makes the inference that the intervention programs primarily boost the

\footnotetext{
${ }^{45}$ In Theory Appendix 7 we derive the expression for the exact change of $S^{k}$. We present equation (29) because it shows the intuition more clearly.
} 
participants' non-cognitive skills. It follows, then, that our macro framework and this body of applied-micro studies share the same policy implication: a real outcome, such as aggregate output or wage, is a better objective for education policies than test scores.

Many education policies likely affect both cognitive and non-cognitive skills. For example, No Child Left Behind, implemented in the U.S. in 2001, is designed to raise test scores, but has been criticized because of the fear that it may adversely affect non-cognitive skills. ${ }^{46}$ Our model provides a potentially useful tool to quantify the net effect of a given policy on aggregate output, if the effects of this policy on cognitive and non-cognitive productivities are available. Using equation (28), we compute, for our sample countries, the marginal output changes following a $1 \%$ increase in $h_{c}^{k}$ or $h_{n}^{k}$, and report these results in columns (4) and (5) of Table 8. For example, a U.S. policy that increases $h_{c}^{U S}$ by $1 \%$ increases U.S. output by $0.85 \%$, holding $h_{n}^{U S}$ fixed. However, this payoff shrinks to 0 if $h_{n}^{U S}$ decreases by $2.95 \%$ $(=1 \% \times 0.85 \% / 0.29 \%)$ instead. ${ }^{47}$

Finally, the effect of a given policy on aggregate output provides an upper bound estimate for the amount of resources to be spent on this policy, or an estimate for its potential returns if we know the amount of resources spent. This means that our model could also be useful for the cost-benefit analysis of education policies.

\section{Open Economy}

So far we have not considered international trade. Without trade, imbalance in humancapital productivities tend to imply low HCQI. With trade, however, this imbalance may help countries specialize and enjoy gains from trade. In this section, we extend our model to incorporate trade, and show how the expression for HCQI changes. We also provide a second external validation for the values of our cognitive and non-cognitive productivities.

\subsection{Setting and Main Equations}

To introduce trade into our model, we assume that the individuals can sell the services of their human capital as intermediate inputs around the globe. The services of cognitive and non-cognitive labor are embodied in traded intermediates. Countries can costlessly export intermediates to an international clearinghouse for factor content and import intermediates

\footnotetext{
${ }^{46}$ A large empirical literature, surveyed in Figlio and Loeb (2011), uses micro data to evaluate the effects of No-Child-Left-Behind on individual outcome.

${ }^{47}$ Columns (4) and (5) show that a $1 \%$ increase in $h_{c}^{k}$ is associated with larger output changes than a $1 \%$ increase in $h_{n}^{k}$. This is because the employment share of the cognitive occupation is higher in the data. This result does not imply that improving the quality of cognitive education carries a higher payoff, because it is unclear how much resources are needed for the $1 \%$ increase in $h_{c}^{k}$ or $h_{n}^{k}$.
} 
at iceberg trade $\operatorname{cost} \tau^{k}$ from this clearinghouse. In order to relate the aggregate quantities of cognitive and non-cognitive human capital to trade and occupation employment shares, we define net exports as quantity ratios

$$
x_{i}^{k}=\frac{L_{i}^{k S}-L_{i}^{k D}}{L_{i}^{k S}}, i=c, n .
$$

For example, if $x_{c}^{k}=-0.5 \%$, country $k$ imports cognitive human capital, the quantity of which is $0.5 \%$ of its aggregate supply. On the other hand, we assume that the final good itself is non-tradeable, because it is used as inputs in the production of human capital.

With trade, equations (6) through (15) still hold. However, factor market clearing in country $k$ is now

$$
\frac{L_{n}^{k D}}{L_{c}^{k D}}=\frac{L_{n}^{k S}}{L_{c}^{k S}} \frac{1-x_{n}^{k}}{1-x_{c}^{k}} .
$$

Equation (31) says that the total quantities of country $k$ 's human capital, $L_{n}^{k S}$ and $L_{c}^{k S}$, can be different from the quantities used in aggregate production, $L_{n}^{k D}$ and $L_{c}^{k D}$, because of trade, $x_{n}^{k}$ and $x_{c}^{k}$ (see Theory Appendix 8 for the other equilibrium equations and definition of equilibrium).

Equation (18) still holds, but the expression for HCQI is now (Theory Appendix 9)

$$
\Omega^{k}=\left(p_{c}^{0}\left(\left(\frac{p_{c}^{0}\left(1-x_{c}^{0}\right)}{p_{c}^{k}\left(1-x_{c}^{k}\right)}\right)^{\frac{1}{\alpha-1}} \frac{h_{c}^{k}}{h_{c}^{0}}\right)^{\theta}+p_{n}^{0}\left(\left(\frac{p_{n}^{0}\left(1-x_{n}^{0}\right)}{p_{n}^{k}\left(1-x_{n}^{k}\right)}\right)^{\frac{1}{\alpha-1}} \frac{h_{n}^{k}}{h_{n}^{0}}\right)^{\theta}\right)^{\frac{1}{\theta}}
$$

Equation (32) says that HCQI remains a weighted power mean involving the ratios of cognitive and non-cognitive productivities. However, it also involves country $k$ 's trade and occupation employment shares, all of which are endogenous variables for $k$. To clearly show the intuition, we consider the case of free trade, where there is a single global price per unit of cognitive and non-cognitive human capital (i.e. $w_{c}^{k}=w_{c}$ and $w_{n}^{k}=w_{n}$ for all $k$ ).

Under free trade, equation (32) simplifies to (Theory Appendix 10)

$$
\Omega^{k}=\left(p_{c}^{0}\left(\frac{h_{c}^{k}}{h_{c}^{0}}\right)^{\theta}+p_{n}^{0}\left(\frac{h_{n}^{k}}{h_{n}^{0}}\right)^{\theta}\right)^{\frac{1}{\theta}} .
$$

The key difference between equations (33) and (19) is in the power coefficients in the construction of the power mean. These coefficients do not include $\alpha$ under free trade, as local labor market demand does not have to equal local labor market supply, by equation (31). This has the effect of increasing the size of these power coefficients relative to the closed economy case; i.e. as if $\alpha \rightarrow \infty$ in equation (19). As a result, being relatively inefficient at producing one type of human capital is less of a drag on HCQI. 
Equation (32), then, represents an intermediate case between (19) and (33). Intuitively, if trade flows have small values, (32) is more similar to (19).

The expression for comparative advantage is now

$$
\frac{h_{c}^{k} / h_{n}^{k}}{h_{c}^{0} / h_{n}^{0}}=\left(\frac{p_{c}^{k} / p_{n}^{k}}{p_{c}^{0} / p_{n}^{0}}\right)^{\frac{1}{\theta}+\frac{1}{\alpha-1}}\left(\frac{1-x_{c}^{k}}{1-x_{n}^{k}}\right)^{\frac{1}{\alpha-1}} .
$$

The first term on the right-hand side of equation (34) is the same as equation (20). The second term in (34) captures the effects of international trade. If we observe, in the data, that country $k$ imports, in the net, the service of cognitive human capital (i.e. $x_{c}^{k}<0$ ), we can infer that country $k$ has a stronger comparative advantage for cognitive human capital than its employment shares suggest, because the cognitive workers in $k$ have chosen their occupation despite import competition.

\subsection{Data, Parameter Values, and Results}

For the trade flows, $x_{c}^{k}$ and $x_{n}^{k}$, we calculate the numbers of cognitive and non-cognitive workers embedded in the net export flows relative to the numbers of these workers in country $k$ 's labor force. ${ }^{48}$ Table 2 shows that the absolute values of these trade flows are small, consistent with the findings of the trade literature.

We now briefly describe how we obtain the parameter values. We maintain the same assumption, (21), under which (22) and (26) continue to hold. Equation (25) also holds, and so we have the same values for $\eta, \theta$ and $h_{c}^{k}$. Equation (27) needs to be modified as (Theory Appendix 11)

$$
\log \left(\frac{Y^{k}}{S^{k} L^{k}} \frac{1}{1-x_{c}^{k}}\right)=F+\frac{\alpha}{\alpha-1} \log \left(1+\frac{p_{n}^{k}\left(1-x_{n}^{k}\right)}{p_{c}^{k}\left(1-x_{c}^{k}\right)}\right)+\log \Theta^{k}
$$

in order to take into account net exports of the services of human capital. Equation (35) gives us the values for $\alpha$ and $\Theta^{k}$. We then plug the values of $\alpha, \theta$, and $h_{c}^{k}$ into equation (34) to obtain the value of $h_{n}^{k}$.

Column (5) of Table 7 shows the results of implementing equation (35). Row (5) of Table 5 summarizes the open-economy parameter values, and Column 6 of Table 8 reports the decomposition based on equations (18) and (32), obtained using these values. ${ }^{49}$ All these results are similar to our benchmark; e.g. the open-economy HCQI has a correlation of 0.918 with the benchmark HCQI. This outcome is intuitive, because trade flows, $x_{c}^{k}$ and $x_{n}^{k}$, tend to be small.

\footnotetext{
${ }^{48}$ In computing the trade flows we follow similar steps as Costinot and Rodriguez-Clare (2014). See Data Appendices 7 and 8 for the details.

${ }^{49}$ We only report the contribution of HCQI, $\left(\Omega^{k}\right)^{1 /(1-\eta)}$, to save space. The contribution of output TFP is column 1 divided by column 6 .
} 
On the other hand, columns (4) and (8) of Table 9 show that the open-economy HCQI has more positive correlation with output per worker than the benchmark HCQI. For our main sample, the correlation for the open-economy HCQI is either marginally significant (output weight) or significant (labor-force-size weight). For our expanded sample, the correlation for the open-economy HCQI is always significant, with higher $R^{2}$ than for the benchmark HCQI.

\subsection{Free-Trade Equilibrium}

As we know from equations (19) and (33), a country's HCQI depends on the extent of openness to factor service trade. While the data suggest that the world is closer to autarky than to free trade, it is instructive to see what HCQI and output per worker would be across countries were international trade frictionless..$^{50}$

To compute the (counterfactual) free-trade equilibrium, we assume that the data we observe (e.g. $L^{k}, Y^{k}, p_{c}^{k}$ and $p_{n}^{k}$ ) are well approximated by the benchmark closed-economy equilibrium, and use the benchmark parameter values. ${ }^{51}$ This counterfactual exercise shows that the iso-HCQI curve changes dramatically from closed economy to free trade. Using equation (33), we compute the free-trade iso-HCQI curve, and plot it in Figure 6. Figure 6 has the same values of cognitive and non-cognitive productivities as Figure 5. In addition, the U.S. occupation employment shares under free trade are similar to their values under closed economy. However, the iso-HCQI curve bends sharply towards the origin in Figure 6, in contrast to Figure 5. We also see, in Figure 6, that several countries that are exceptional along the cognitive dimension in human capital production (e.g. Hong Kong and Slovenia) lie above the iso-HCQI curve, meaning that they would have higher overall quality for human capital than the U.S. under free trade. These results are intuitive: the countries that have imbalanced productivities in human-capital production benefit from being able to specialize in the occupations in which they excel.

To help visualize this intuition, we plot the changes in HCQI against non-cognitive and cognitive productivities in Figure 7. In this 3D plot, the countries in the middle, who have

\footnotetext{
${ }^{50}$ Our motivations for this world-is-flat counterfactual are as follows. First, free trade might be more useful for regional differences within countries, complementing the economic geography literature (e.g. Krugman 1991, Davis and Weinstein 2002, Redding and Sturm 2008, Allen and Arkolakis 2014). Second, internationally, while service trade has been growing faster than goods trade (e.g. wto.org), it has seen less liberalizations than goods trade, and so has more scope for further liberalization. Finally, new technology may decrease the cost of service trade.

${ }^{51}$ Note that we are unable to apply the standard techniques of Deckle, Eaton and Kortum (2008), or DEK 2008 , because $x_{c}^{k}=x_{n}^{k}=0$ under closed economy. However, our computation still has the flavor of DEK 2008 , in that we do not need to make additional assumptions about unidentified parameters. See Theory Appendices 12 and 13 for the details.
} 
balanced cognitive and non-cognitive productivities, have limited changes in HCQI. However, changes in HCQI are large for the countries on the edges of the figure, who have strong comparative advantages in either cognitive or non-cognitive human capital. For example, S. Korea would see a $24.3 \%$ increase in HCQI, the Netherlands $14.2 \%$, and Belgium $13.2 \%$.

These changes in HCQI are closely related to output gains from trade. Equation (18) implies that

$$
\widehat{Y}^{k}=\widehat{Y}^{0}\left(\widehat{\Omega}^{k}\right)^{\frac{1}{1-\eta}} .
$$

Equation (36) says that country $k$ 's gains from trade is equal to the change in its HCQI, amplified by the power $1 /(1-\eta)$, multiplied by the base country's (here the U.S.) gains from trade. ${ }^{52}$

Column (1) of Table 10 shows the changes in HCQI from closed-economy to free trade. Column (2) reports the output changes in this movement. We see that column (1) is very similar to column (2), because U.S. gains from trade are small, ${ }^{53}$ and so is the power amplification, $1 /(1-\eta)$.

Finally, we explore the policy implications under the free-trade equilibrium, by computing the marginal changes in aggregate output in response to a $1 \%$ increase in $h_{c}^{k}$ or $h_{n}^{k}$. ${ }^{54}$ We report the results in columns (3) and (4) of Table 10. They are quite different from the closed-economy results in Table 8, because comparative advantage plays a major role. For the countries with strong comparative advantages in non-cognitive human capital (e.g. Belgium, Netherlands, U.K. and U.S.), a $1 \%$ increase in $h_{n}^{k}$ elicits much larger output responses under free trade than under closed economy, because this change reinforces these countries' comparative advantages. In comparison, the $1 \%$ increase in $h_{n}^{k}$ leads to very limited output responses for the countries with strong comparative advantages in cognitive human capital (e.g. France, Hong Kong and S. Korea).

\subsection{External Validation: Patterns of Trade}

We now provide the second external validation for our values of non-cognitive productivities using industry level trade data. Our idea is that the $h_{c}^{k}$ and $h_{n}^{k}$ values reflect countries' relative abundance in non-cognitive human capital, a source of comparative advantage. It

\footnotetext{
${ }^{52}$ We show (Theory Appendix 14) that equation (36) can be re-written as the counter-part of the ACR2012 formula for our model. We also show (Theory Appendix 15) that a country must gain from trade as long as it is a net importer of at least one type of factor service (i.e. $\widehat{Y}^{k}>1$ if $x_{i}^{k}<1$ for at least one $i$ ).

${ }^{53}$ U.S. gains from trade are small because she has the largest labor-force size and second highest output TFP in our main sample. In Theory Appendix 16, we consider an alternative scenario of adding Japan and China, and obtain larger gains for the U.S.

${ }^{54}$ We derive the counterpart of equation (28) in Theory Appendix 17. This expression relates countries' output changes to changes in their absolute advantage, comparative advantage, and terms of trade.
} 
thus follows that non-cognitive abundant countries should be net exporters of the industries that use non-cognitive human capital intensively.

To take this prediction to the data, we follow the literature (e.g. Nunn 2007, Bombardini, Gallipoli and Pupato 2012) and examine the correlation between the patterns of trade and the interactions between relative factor abundance and factor-use intensities. For each country in our sample, we collect aggregate import and export for the 31 NAICS manufacturing industries in the 2000 U.S. census, and the 9 1-digit service industries in the UN servicetrade database (see Data Appendix 7 for more details). To measure trade patterns, we calculate net export divided by the sum of import and export by industry by country. For each country, we measure its relative abundance in non-cognitive human capital, physical capital and skilled labor as, respectively, the ratio of $h_{n}^{k}$ to $h_{c}^{k}$, the ratio of physical capital stock to population, and the fraction of college-educated labor force. For each industry, we measure the intensities of non-cognitive human capital, physical capital and skilled labor using U.S. data. Finally, we control for industry fixed effects and country fixed effects.

Table 11 reports the results. Column (1) includes only the interaction for non-cognitive human capital. We add the interaction for physical capital in column (2), and then the interaction for skilled labor in column (3). The interaction for non-cognitive human capital has positive and significant coefficient estimates in all specifications. These results suggest that our $h_{c}^{k}$ and $h_{n}^{k}$ values are useful for the variation of trade patterns by industry by country, even though we did not use such variation to obtain them. In addition, the $h_{c}^{k}$ and $h_{n}^{k}$ values mainly reflect the supply of (not demand for) human capital, because the countries with high $h_{n}^{k} / h_{c}^{k}$ tend to have large net exports (not imports) of non-cognitive intensive industries.

\section{Additional Extensions and Robustness}

In this section, we show that we obtain similar results in the following scenarios. First, we incorporate the scale of PISA scores into our quantification. This is a robustness check on how we relate PISA scores to cognitive human capital. Second, we explicitly model noncognitive and cognitive occupations as packages of skills. Third, we explore alternative ways to classify non-cognitive and cognitive occupations in the data. Finally, we experiment with alternative parameter values.

\subsection{Test Score Scale}

One concern is that the PISA score, whose mean is normalized to 500 and standard deviation to 100 , may be inconsistent with the way we have normalized the unit of cognitive human 
capital. ${ }^{55}$ A more general way to scale PISA scores is, $\left(S^{k}\right)^{\delta}$, where $\delta>0$ is a scaling factor. We have so far assumed that $\delta=1$. In this subsection we conduct robustness analyses to show that scaling is not a serious concern.

To obtain an estimate for $\delta$, we go back to the wage-AFQT regressions of Table 1 , which anchor the AFQT scores to wages, and rescale AFQT to have mean 500 and standard deviation 100, and use the log of this score in the estimation. Column (7) of Table 1 shows an estimate of 0.912 for the elasticity of wage with respect to PISA-scaled AFQT score. ${ }^{56}{ }^{57}$ We next turn to our model, where the quantity of an individual's cognitive human capital (in efficiency equivalent units) is given by equations (2) and (3). These choices of units imply that across individuals, wage moves one-for-one with the quantity of cognitive human capital (Theory Appendix 18). Combining this result with column (7) of Table 1, we infer that the elasticity of the quantity of cognitive human capital with respect to PISA-scaled AFQT score is also 0.912, and so we set $\delta=0.912 .{ }^{58}$

We replace $S^{k}$ in equation (26) with $\left(S^{k}\right)^{\delta}$ and re-estimate. The results, shown in column (5) of Table 4, are similar to column (1), our benchmark specification. We then replace $S^{k}$ with $\left(S^{k}\right)^{\delta}$ in equation (27) and re-esetimate. The results, shown in column (6) of Table 7 , are similar to our benchmark, column (1). In row (6) of Table 5, we list the $\theta$ and $\alpha$ values of this specification and show that we obtain similar values for non-cognitive and cognitive productivities and HCQI.

Finally, we take the opposite approach of rescaling the PISA scores to have the same scale as the raw AFQT scores. In the NLSY79 data, which we use for Table 1, the raw AFQT score has a mean of 38.6 and standard deviation of 27.8. We re-estimate the wage-AFQT regression using the log of raw AFQT score. The wage elasticity for AFQT is now 0.150, because of re-scaling, but the other aspects of the results are similar to column (7) of Table 1. We then re-scale PISA math score, in macro data, to also have mean 38.6 and standard deviation 27.8, and use $\left(S^{k}\right)^{\delta}, \delta=0.150$, in equations (26) and (27). The results are shown in column (6) of Table 4 and in column (7) of Table 7. They are also similar to our benchmark specifications. ${ }^{59}$

\footnotetext{
${ }^{55}$ Our results use the log of PISA scores, and so they are unaffected if the normalization is for standard deviation only.

${ }^{56}$ We are not aware of any study that examines the relationship between individuals' PISA scores and the wages that they obtain later in their lives.

${ }^{57}$ The coefficient estimate is 0.706 for the non-cognitive sub-sample and 0.927 for the cognitive sub-sample; i.e. changing the scale of the AFQT scores does not affect our occupation classification.

${ }^{58}$ Cubas et al (2016) also consider the specification $\left(S^{k}\right)^{\delta}$, but assume that $\left(S^{k}\right)^{\delta}$ maps into the location of the talent distribution (which is like $T_{c}$ in our model). The other aspects of their model are also different from ours. As a result, they obtain a different value for $\delta$.

${ }^{59}$ We have 31 observations in the expanded sample because 3 countries' PISA math scores become negative after re-scaling.
} 


\subsection{Cognitive- and Non-Cognitive-Intensive Occupations}

In this subsection, we formalize the intuition that non-cognitive and cognitive attributes are packages of skills. We do so by assuming that occupations require both skills but differ in the mix of skills required. To be specific, suppose that the workers accumulate human capital for occupation $i, i=1,2$, according to

$$
\begin{aligned}
l_{i}^{k} & =h_{c}(e)^{\beta_{i}} h_{n}(e)^{1-\beta_{i}} \varepsilon_{i}, \\
h_{c}(e) & =h_{c}^{k} e^{\eta}, h_{n}(e)=h_{n}^{k} e^{\eta}
\end{aligned}
$$

In this expression, $\beta_{i}$ captures the cognitive intensity of occupation $i$. Let $\beta_{1}>\beta_{2}$; i.e. occupation 1 is cognitive-intensive. $h_{c}^{k}$ and $h_{n}^{k}$ are the cognitive and non-cognitive productivities. We adapt the other aspects of our setting in section 3 for occupations; e.g. workers now draw their birth talents for occupations 1 and $2, \varepsilon_{1}$ and $\varepsilon_{2}$, from the Frechet distribution, (1). We show that (Theory Appendix 19)

Proposition 3 Let $\widetilde{h_{i}^{k}}=\left(h_{c}^{k}\right)^{\beta_{i}}\left(h_{n}^{k}\right)^{1-\beta_{i}}, i=1,2$. Our results in sections 3 and 4.1 hold for $\widetilde{h_{i}^{k}}$. e.g. equation (18) continues to hold, and HCQI is

$$
\Omega^{k} \equiv\left(p_{1}^{0}\left(\frac{\widetilde{h_{1}^{k}}}{\widetilde{h_{1}^{0}}}\right)^{\frac{\theta(\alpha-1)}{\phi}}+p_{2}^{0}\left(\widetilde{\widetilde{h_{2}^{k}}} \widetilde{\widetilde{h_{2}^{0}}}\right)^{\frac{\theta(\alpha-1)}{\phi}}\right)^{\frac{\phi}{\theta(\alpha-1)}} .
$$

The intuition of our results is as follows. Both occupations now use cognitive and noncognitive human capital, and so both occupations are packages of skills. What matters for human-capital productivity of country $k$, then, is the productivities of these packages, $\widetilde{h_{1}^{k}}$ and $\widetilde{h_{2}^{k}}$. On the other hand, the structure and mechanism of our model remain unchanged, relative to sections 3 and 4.1 , and so all the results there hold for $\widetilde{h_{1}^{k}}$ and $\widetilde{h_{2}^{k}}$.

Proposition 3 has three quantitative implications. First, we can interpret the values of "non-cognitive productivity" and "cognitive productivity" as values of $\widetilde{h_{2}^{k}}$ and $\widetilde{h_{1}^{k}}$. Second, with this interpretation, the procedure for computing comparative advantage, which use equation (20), remains unchanged. Third, we can compute HCQI in the same way. It then follows that we will obtain similar HCQI values if we have similar values for cognitive productivities.

The one substantive change is in the way we obtain the values of cognitive productivities. The counterpart of equation (26) (Theory Appendix 20) is

$$
\ln \frac{S^{k}}{\left(Y^{k} / L^{k}\right)^{\eta}}=\text { constant }+\left(1-\frac{1}{\theta}\right) \ln \left(p_{1}^{k}\right)+\ln \widetilde{h_{1}^{k}}+\ln \Lambda\left(p_{1}^{k}\right) .
$$

Relative to (26), equation (38) is augmented by the term $\ln \Lambda\left(p_{1}^{k}\right)$, which represents (one plus) the non-cognitive-intensive occupation's contribution relative to the cognitive-intensive 
occupation. While the expression for $\ln \Lambda\left(p_{1}^{k}\right)$ is complicated, ${ }^{60}$ there are multiple ways to evaluate its variation across countries in our data.

First, we compute $\ln \frac{S^{k}}{\left(Y^{k} / L^{k}\right)^{\eta}}-\left(1-\frac{1}{\theta}\right) \ln \left(p_{1}^{k}\right)$ using our data and the literature's estimate of $\theta=2$. This variable corresponds to $\ln \widetilde{h_{1}^{k}}+\ln \Lambda\left(p_{1}^{k}\right)$, by equation (38), and we find that it has little correlation with $\ln p_{1}^{k}$ in our data (correlation coefficient $=-0.0065$, with p-value of 0.9749$)$. This result suggests that the positive correlation between normalized test score, $\ln \frac{S^{k}}{\left(Y^{k} / L^{k}\right)^{\eta}}$, and log cognitive employment share, $\ln \left(p_{1}^{k}\right)$, which we document in section 5 , remains useful evidence for our model, and for our occupation classification. Second, we experiment with proxying $\ln \Lambda\left(p_{1}^{k}\right)$ using the 2 nd through 4 th powers of $\ln p_{1}^{k}$. We regress $\ln \frac{S^{k}}{\left(Y^{k} / L^{k}\right)^{\eta}}-\left(1-\frac{1}{\theta}\right) \ln \left(p_{1}^{k}\right)$ on $\left(\ln p_{1}^{k}\right)^{2}$ through $\left(\ln p_{1}^{k}\right)^{4}$, first individually, and then jointly, and obtain statistically insignificant coefficient estimates. We also experimented with adjusting our cognitive productivities using these specifications (even though the coefficient estimates are not significant), and obtained similar results (see Data Appendix 9). These results suggest that the cross-country variation of $\ln \Lambda\left(p_{1}^{k}\right)$ in our data may have limited effects on the values of our cognitive productivities. They also imply that we obtain similar HCQI values, because we retain the same values for comparative advantage, and the bulk of the variation in HCQI comes from the non-cognitive dimension.

\subsection{Alternative Occupation Classification}

So far we have used the numerical values of occupation characteristics to classify occupations as cognitive or non-cognitive. As the literature that classifies occupations often uses ratios of the characteristics ${ }^{61}$ instead of levels, we experiment with ratios, following the approach of Autor, Levy and Murnane (2003). We specify two types of cognitive characteristics, math and information processing. For each category we collect several O*NET characteristics and compute the first principal component. We then calculate the ratio of the leadership principal component, which we have been using, to the sum of the principal components of leadership, math and information processing. Looking at occupation-characteristics data, we find that this ratio is qualitatively similar to the measures we have used; e.g. it has a correlation coefficient of 0.648 with the numerical value of leadership principal component, and a higher mean for our non-cognitive occupations than for cognitive occupations. When we estimate the wage-AFQT regressions, however, we obtain weaker results; i.e. while we obtain smaller coefficient estimates for the non-cognitive sub-sample than for the cognitive

\footnotetext{
${ }^{60}$ We spell out this expression in Theory Appendix 20. There, we also show that, under some technical assumptions, we can make the inference of $\beta_{2}<\beta_{1}$ from the result that the wage-AFQT regression in Table 1 delivers a smaller coefficient estimate for the non-cognitive subsample (see also note 57 ).

${ }^{61}$ Examples of numerical values include Hummels et al. (2014) and Deming (2017). Examples of ratios include Ebenstein, Harrison, McMillan and Phillips (2014). Autor, Levy and Murnane (2003) use both.
} 
sub-sample, the difference is not statistically significant. ${ }^{62}$

One may also be concerned that the O*NET occupation scores are noisy and that their values are ordinal but not cardinal. This is why we focus on the dichotomy between the non-cognitive group and the cognitive group; i.e. our implicit assumption is that occupations have similar rankings across countries in terms of the importance of leadership (see also note 24). This assumption implies that the type of human capital a worker has acquired in her birth country will also be useful after she emigrates to the U.S.; i.e. we should observe a positive correlation between countries' comparative advantages for non-cognitive human capital, $h_{n}^{k} / h_{c}^{k}$, and the fractions of their U.S. emigrants in non-cognitive occupations. ${ }^{63}$ We use the 2000 U.S. Census to investigate this prediction. We follow the literature (e.g. Hendricks 2002, Schoellman 2012) and focus on the adult immigrants who arrived in the U.S. after their expected graduation dates (see Data Appendix 10 for the details). Figure 8 plots, for our main-sample countries, their U.S. emigrants' shares in non-cognitive occupations against their comparative advantages for non-cognitive human capital. It shows a clear positive correlation $(0.618$ with $\mathrm{p}$-value $=0.001)$, consistent with our assumption that occupational requirements for skills are similar across countries.

Finally, we have also experimented with measuring non-cognitive skills using the following O*NET characteristics: investigative skills, originality, social skills, and artistic talents. As we show in Data Appendix 10, when we use investigative skills, originality or social skills, we find that the wage-AFQT regressions have larger coefficient estimates for the non-cognitive sub-sample. When we use artistic talents, we find that the artists with high test scores earlier in life tend to have low wages later. However, artists account for less than $1 \%$ of the labor force.

In summary, we are not proposing leadership as the measure for non-cognitive skills; instead, we have shown that it is a useful measure that enables us to compare countries' productivities for non-cognitive human capital in the absence of a direct measure along the non-cognitive dimension. It is beyond the scope of our paper to explore all the occupation characteristics used in the literature, or those in $\mathrm{O}^{*} \mathrm{NET}$. In addition, this occupation classification is consistent with both micro data (Table 1) and macro data (Tables 4 and 7).

\subsection{Alternative Parameter Values}

Rows (3)-(6) of Table 5 recap our $\theta$ and $\alpha$ values under the alternative specifications and samples that we have discussed. They also show that we obtain similar values of cognitive

\footnotetext{
${ }^{62}$ See Data Appendix 10 for more details. There, we also show that we obtain similar results using other specifications.

${ }^{63}$ We do not expect this correlation to be perfect; e.g. the restrictiveness of U.S. immigration policy may vary across countries and across occupations.
} 
and non-cognitive productivities, and HCQI, under these alternative $\theta$ and $\alpha$ values. Row (7) of Table 5 shows that we also get similar results when we set $\theta=4$ and $\alpha=2$.

\section{Conclusion and Discussions}

We have developed a GE framework, in the spirit of Roy (1951), to model the productions of cognitive and non-cognitive human capital. Our stylized model allows us to use revealed comparative advantage to infer countries' non-cognitive and cognitive productivities without a direct measure for the non-cognitive dimension. Our model also delivers analytical expressions for how non-cognitive and cognitive productivities relate to HCQI, and how HCQI relates to output per worker.

Our framework allows us to obtain the values of the full set of parameters using publically available data for a sample of mostly high-income countries. Our quantification exercises show that hard-to-measure non-cognitive human capital is important for HCQI, and HCQI is important for output per worker. Many countries that perform well on international tests have below-the-average productivities on non-cognitive human capital, and this is large enough to drag down their HCQI. In addition, policy reforms that increase test score may reduce aggregate output, and vice versa. This points to the importance of spelling out the impacts of education policies on aggregate output when we formulate their objectives and conduct cost-benefit analyses. Here, our model provides a potentially useful tool.

While we show that globalization and associated trade in factor services are critical, theoretically, in assessing the quality of a country's human capital, the data suggest that the world is closer to autarky than it is to free trade. For the moment at least, educational institutions that focus on one type of human capital to the great detriment of another are the source of substantially lower income per capita; i.e. imbalance is a source of weakness. However, the countries with imbalanced human-capital productivities would reap substantial output gains if countries were to engage in free trade of the services of human capital; i.e. under free trade, imbalance would be a source of strength.

We now discuss additional caveats. First, in our quantitative exercises, although we do not need direct measures of both cognitive and non-cognitive human capital, we need at least one. This measure must be available in macro data, for cross-country comparison, and in micro data as well, to guide occupation classification. The measure we have used is test score. ${ }^{64}$ We understand that test score is not perfect; e.g. high-stake tests may distort teachers' incentives (e.g. Neal and Schanzenbach 2010), while low-stake tests may not solicit

\footnotetext{
${ }^{64}$ Another widely used measure for human capital is returns to schooling in Mincer wage regressions (e.g. Bils and Klenow 2000, Banerjee and Duflo 2005, Schoellman 2012). We are unable to use this measure because it's unclear how it differs for the cognitive dimension vs. the non-cognitive dimension.
} 
enough student efforts (e.g. Akyol, Krishna and Wang 2018). Should a better measure become available in the future, it can be incorporated into our framework.

Second, the different ways in which countries produce human capital may provide incentives for immigration; e.g. those educated in high relative-cognitive-productivity countries

(e.g. S. Korea) may have incentives to migrate to where such relative productivities are low (e.g. the U.S.). This intuition for immigration is similar to trade, which we have in our model. In addition, in our model, the individuals who migrate at young ages are not distinguishable from native-borns, and it is unclear whether data for immigrants show how much human capital they accumulate in their birth countries. If such data is available for future research, it will be interesting to explore the implications of the cross-country differences in cognitive and non-cognitive productivities for the welfare gains of immigration.

Finally, we have taken cognitive and non-cognitive productivities as exogenous parameters. Our motivation is to quantify these parameters and to draw out their implications for HCQI and output per worker, given that previous estimates of their values do not exist. Could policies affect the values of cognitive and non-cognitive productivities? If so, what policies? How much resources do these policies require? Could there be optimal policies, and how might they vary in closed vs. open economies? We leave these questions for future research.

\section{References}

[1] Acemoglu, Daron, Simon Johnson, and James A. Robinson. "The Colonial Origins of Comparative Development: An Empirical Investigation." American Economic Review 91.5 (2001): 1369-1401.

[2] Akyol, Ş. Pelin, Kala Krishna, and Jinwen Wang. Taking PISA Seriously: How Accurate are Low Stakes Exams?. No. w24930. National Bureau of Economic Research, 2018.

[3] Allen, Treb, and Costas Arkolakis. "Trade and the Topography of the Spatial Economy." The Quarterly Journal of Economics 129.3 (2014): 1085-1140.

[4] Almlund, M., Duckworth, A. L., Heckman, J., \& Kautz, T. (2011). Personality psychology and economics. In Handbook of the Economics of Education (Vol. 4, pp. 1-181). Elsevier.

[5] Altonji, Joseph G., and Charles R. Pierret. "Employer learning and statistical discrimination." The Quarterly Journal of Economics 116.1 (2001): 313-350.

[6] Arkolakis, Costas, Arnaud Costinot, and Andrés Rodríguez-Clare. "New trade models, same old gains?" The American Economic Review 102.1 (2012): 94-130. 
[7] Atkin, David, 2016. "Endogenous Skill Acquisition and Export Manufacturing in Mexico", American Economic Review 106(8), 2046-2085.

[8] Autor, David H., Frank Levy and Richard J. Murname, 2003. "The Skill Content of Recent Technological Change: An Empirical Exploration", Quarterly Journal of Economics 118(4).

[9] Banerjee, Abhijit V., and Esther Duflo. "Growth theory through the lens of development economics." Handbook of economic growth 1 (2005): 473-552.

[10] Barro, Robert J. and Sala-i-Martin, Xavier. Economic Growth. New York: McGrawHill, 1995.

[11] Behrman, J. R., Parker, S. W., Todd, P. E., \& Wolpin, K. I. (2015). Aligning learning incentives of students and teachers: results from a social experiment in Mexican high schools. Journal of Political Economy, 123(2), 325-364.

[12] Bils, Mark, and Peter J. Klenow. "Does schooling cause growth?." American economic review 90.5 (2000): 1160-1183.

[13] Blanchard, Emily and William Olney, 2017. "Globalization and Human Capital Investment: Export Composition Drives Educational Attainment", Journal of International Economics, 106, 165-183.

[14] Bombardini, Matilde, Giovanni Gallipoli, and Germán Pupato. "Skill dispersion and trade flows." American Economic Review 102.5 (2012): 2327-48.

[15] Burnstein, Ariel, Eduardo Morales and Jonathan Vogel, 2016. "Changes in BetweenGroup Inequality: Computers, Occupations and International Trade", mimeo.

[16] Card, David, and Thomas Lemieux. "Can falling supply explain the rising return to college for younger men? A cohort-based analysis." The Quarterly Journal of Economics 116.2 (2001): 705-746.

[17] Casselli, F. 2005. "Accounting for Cross-Country Income Differences." in Handbook of Economic Growth.

[18] Caselli, Francesco, I. I. Coleman, and Wilbur John. "The world technology frontier." American Economic Review 96.3 (2006): 499-522.

[19] Chetty, Raj, John N. Friedman, Nathaniel Hilger, Emmanuel Saez, Diane W. Schanzenbach, and Danny Yagan. 2011. "How Does Your Kindergarten Classroom Affect Your Earnings? Evidence from Project STAR." Quarterly Journal of Economics, 126(4): $1593-1660$. 
[20] Costinot, Arnaud and Andrés Rodríguez-Clare, 2014. "Trade Theory with Numbers: Quantifying the Consequences of Globalization", in Handbook of International Economics, edts. Gita Gopinath, Elhanan Helpman, and Kenneth Rogoff, vol. 4, chapter 4.

[21] Cunha, Flavio, James Heckman and Susanne Schennach. "Estimating the Technology of Cognitive and Non-cognitive Skill Formation”, Econometrica 78(3), May 2010, 883-931.

[22] Davis, Donald R., and David E. Weinstein. "An account of global factor trade." American Economic Review 91.5 (2001): 1423-1453.

[23] Davis, Donald and David Weinstein. "Bones, bombs, and break points: the geography of economic activity." The American Economic Review 92.5 (2002): 1269-1289.

[24] Deckle, Jonathan Eaton, and Samuel Kortum. 2008. "Global Rebalancing with Gravity." International Monetary Fund Staff Papers 55: 511-540

[25] Deming, David. 2009. "Early Childhood Intervention and Life-Cycle Skill Development: Evidence from Head Start." American Economic Journal: Applied Economics 1(3): 11134 .

[26] Deming, David J. "The growing importance of social skills in the labor market." The Quarterly Journal of Economics 132.4 (2017): 1593-1640.

[27] Deming, David J. "The value of soft skills in the labor market." NBER Reporter 4 (2017): 7-11.

[28] Duncan, Greg J., and Katherine Magnuson. "Investing in preschool programs." Journal of Economic Perspectives 27.2 (2013): 109-32.

[29] Eaton, Jonathan and Samuel Kortum, 2002. "Technology, Geography and Trade", Econometrica, 70(5), 1741-1779.

[30] Ebenstein, A., Harrison, A., McMillan, M., Phillips, S. Estimating the impact of trade and offshoring on American Workers Using the Current Population Surveys. Review of Economics and Statistics 96(4): 581-595.

[31] Figlio, David and Susanna Loeb, 2011. "School Accountability", in Handbook of the Economics of Education, Volume 3, Edited by Eric Hanushek, Stephen Machin and Ludger Woessmann, Elsevier North-Holland: Amsterdam, 383-421.

[32] Findlay, Ronald and Henryk Kierzkowski, 1983. "International Trade and Human Capital: A Simple General Equilibrium Model", Journal of Political Economy, 91(6), 957-978. 
[33] Galle, Simon, Andres Rodriguez-Clare, and Moises Yi. 2018. "Slicing the Pie: Quantifying the Aggregate and Distributional Effects of Trade." Mimeo University of CaliforniaBerkeley.

[34] Garces, Eliana, Duncan Thomas, and Janet Currie. 2002. "Longer-Term Effects of Head Start." American Economic Review 92(4): 999 -1012.

[35] Hall, Robert E. and Charles I. Jones, "Why Do Some Countries Produce So Much More Output per Worker than Others?", Quarterly Journal of Economics, February 1999, Vol. 114, pp. 83-116.

[36] Hanushek, E., "Education Production Functions", The New Palgrave Dictionary of Economics, 2008.

[37] Hanushek, Eric A., and Dennis D. Kimko. "Schooling, labor-force quality, and the growth of nations." American economic review 90.5 (2000): 1184-1208.

[38] Heckman, James J., Seong Hyeok Moon, Rodrigo Pinto, Peter Savelyev, and Adam Yavitz. 2010. "A New Cost-Benefit and Rate of Return Analysis for the Perry Preschool Program: A Summary." NBER Working Paper 16180.

[39] Hanushek, Eric, and Ludger Woessman. 2011. "How Much do Educational Outcomes Matter in OECD Countries?" Economic Policy 26(67): 427-491.

[40] Heckman, James J., and Tim Kautz. "Hard evidence on soft skills." Labour economics 19.4 (2012): 451-464.

[41] Heckman, James J., and Tim Kautz. Fostering and measuring skills: Interventions that improve character and cognition. No. w19656. National Bureau of Economic Research, 2013.

[42] Heckman, James J. and Yona Rubinstein. 2001. "The Importance of Noncognitive Skills: lessons from the GED Testing Program", American Economic Review Papers \& Proceedings 91(2): 145-149.

[43] Hendricks, Lutz. "How important is human capital for development? Evidence from immigrant earnings." American Economic Review 92.1 (2002): 198-219.

[44] Hsieh, Chang-Tai, and Peter J. Klenow. "Misallocation and manufacturing TFP in China and India." The Quarterly journal of economics 124.4 (2009): 1403-1448.

[45] Hsieh, Chang-Tai, Erik Hurst, Charles Jones and Peter Klenow. "The Allocation of Talent and U.S. Economic Growth", NBER working paper 18693. 
[46] Hummels, D., Jørgensen, R., Munch, J., \& Xiang, C. (2014). The wage effects of offshoring: Evidence from Danish matched worker-firm data. American Economic Review, 104(6), 1597-1629.

[47] Hummels, David, Jakob R. Munch, and Chong Xiang. "Offshoring and Labor Markets." Journal of Economic Literature.

[48] Jackson, Kirabo, Rucker C. Johnson, and Claudia Persico. 2016. "The Effects of School Spending on Educational and Economic Outcomes: Evidence from School Finance Reforms," The Quarterly Journal of Economics 131(1): 157-218.

[49] Jones, Benjamin. 2014. "The Human Capital Stock: A Generalized Approach." American Economic Review 104(11): 3752-3777.

[50] Klenow, Peter, and Andres Rodriquez-Clare. 1997. "The Neoclassical Revival in Growth Economics: Has It Gone Too Far?" NBER Working paper.

[51] Krugman, Paul. "Increasing returns and economic geography." Journal of political economy 99.3 (1991): 483-499.

[52] Kuhn, Peter, and Catherine Weinberger. 2005. "Leadership Skills and Wages." Journal of Labor Economics 23(3): 395-436.

[53] Lagakos, David, and Michael E. Waugh. "Selection, agriculture, and cross-country productivity differences." American Economic Review 103.2 (2013): 948-80.

[54] Lee, Eunhee, 2017. "Trade, Inequality, and the Endogenous Sorting of Heterogeneous Workers", mimeo, University of Maryland.

[55] Li, Bingjing, 2016. "Export Expansion, Skill Acquisition and Industry Specialization: Evidence from China", mimeo, National University of Singapore.

[56] Ludwig, Jens, and Douglas L. Miller. 2007. "Does Head Start Improve Children's Life Chances: Evidence from a Regression Discontinuity Design." Quarterly Journal of Economics 122(1): $159-208$.

[57] Lundberg, Shelly. "Non-cognitive skills as human capital." Education, Skills, and Technical Change, and Future US GDP Growth. University of Chicago Press, 2017.

[58] Malmberg, Hannes. 2017. "Human Capital and Development Accounting Revisited." mimeo Institute for International Economic Studies.

[59] Neal, Derek A., and William R. Johnson, "The Role of Premarket Factors in Black White Wage Differences", Journal of Political Economy 104 (5), October 1966, 869-895. 
[60] Nunn, Nathan. "Relationship-specificity, incomplete contracts, and the pattern of trade." The Quarterly Journal of Economics (2007): 569-600.

[61] Ohnsorge, Franziska and Daniel Trefler, "Sorting it Out: International Trade and Protection with Heterogeneous Workers." Journal of Political Economy 115(5) (2007): 868892.

[62] Redding, Stephen J., and Daniel M. Sturm. "The costs of remoteness: Evidence from German division and reunification." The American Economic Review 98.5 (2008): 17661797.

[63] Roy, Arthur. 1951. "Some Thoughts on the Distribution of Earnings." Oxford Economic Papers 3(2): 135-146.

[64] Seth, Michael J. Education fever: Society, politics, and the pursuit of schooling in South Korea. University of Hawaii Press, 2002.

[65] Schmitt, D. P., Allik, J., McCrae, R. R., \& Benet-Martínez, V. (2007). The geographic distribution of Big Five personality traits: Patterns and profiles of human self-description across 56 nations. Journal of cross-cultural psychology, 38(2), 173-212.

[66] Schoellman, Todd. "Education quality and development accounting." The Review of Economic Studies 79.1 (2011): 388-417.

[67] Schweinhart, Lawrence J., Jeanne Montie, Zongping Xiang, W. Steven Barnett, Clive R. Belfield, and Milagros Nores. 2005. Lifetime Effects: The HighScope Perry Preschool Study through Age 40. Monographs of the HighScope Educational Research Foundation,14. Ypsilanti, MI: HighScope Press.

[68] Trefler, Daniel. "The case of the missing trade and other mysteries." The American Economic Review (1995): 1029-1046.

[69] US Department of Health and Human Services, Administration for Children and Families. 2010. Head Start Impact Study: Final Report. Washington, DC.

[70] Webb, L. Dean, Arlene Metha, and Kenneth Forbis Jordan. Foundations of American education. Merrill, 2013.

[71] Willis, Robert and Sherwin Rosen. "Education and Self-Selection", Journal of Political Economy 87(5), October 1979, S7-S36. 
Figure 1 Histogram of Employment Share of Non-cognitive Occupations

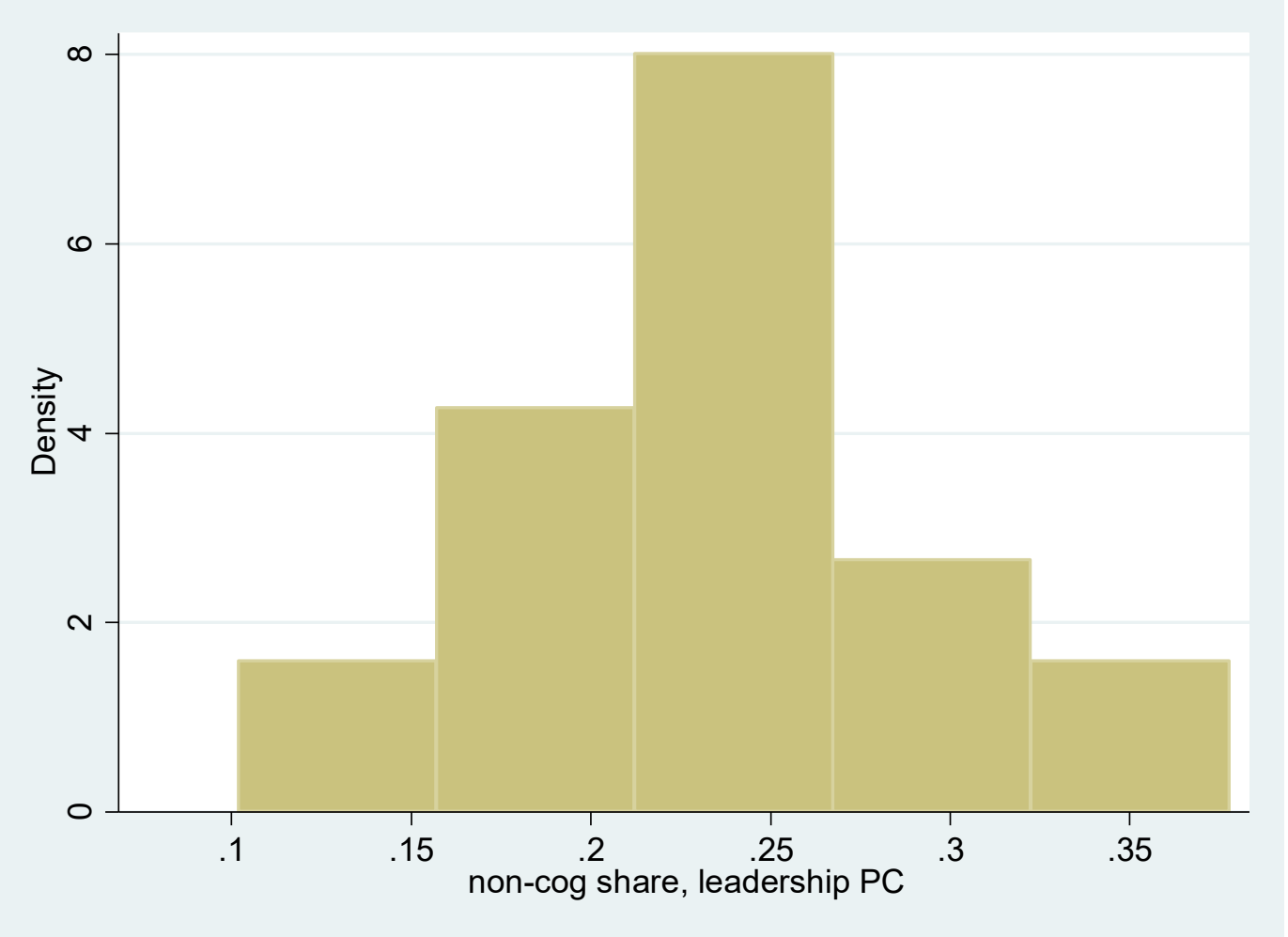


Figure 2 Normalized Test Score and Cognitive Employment Share 2a. Main Sample

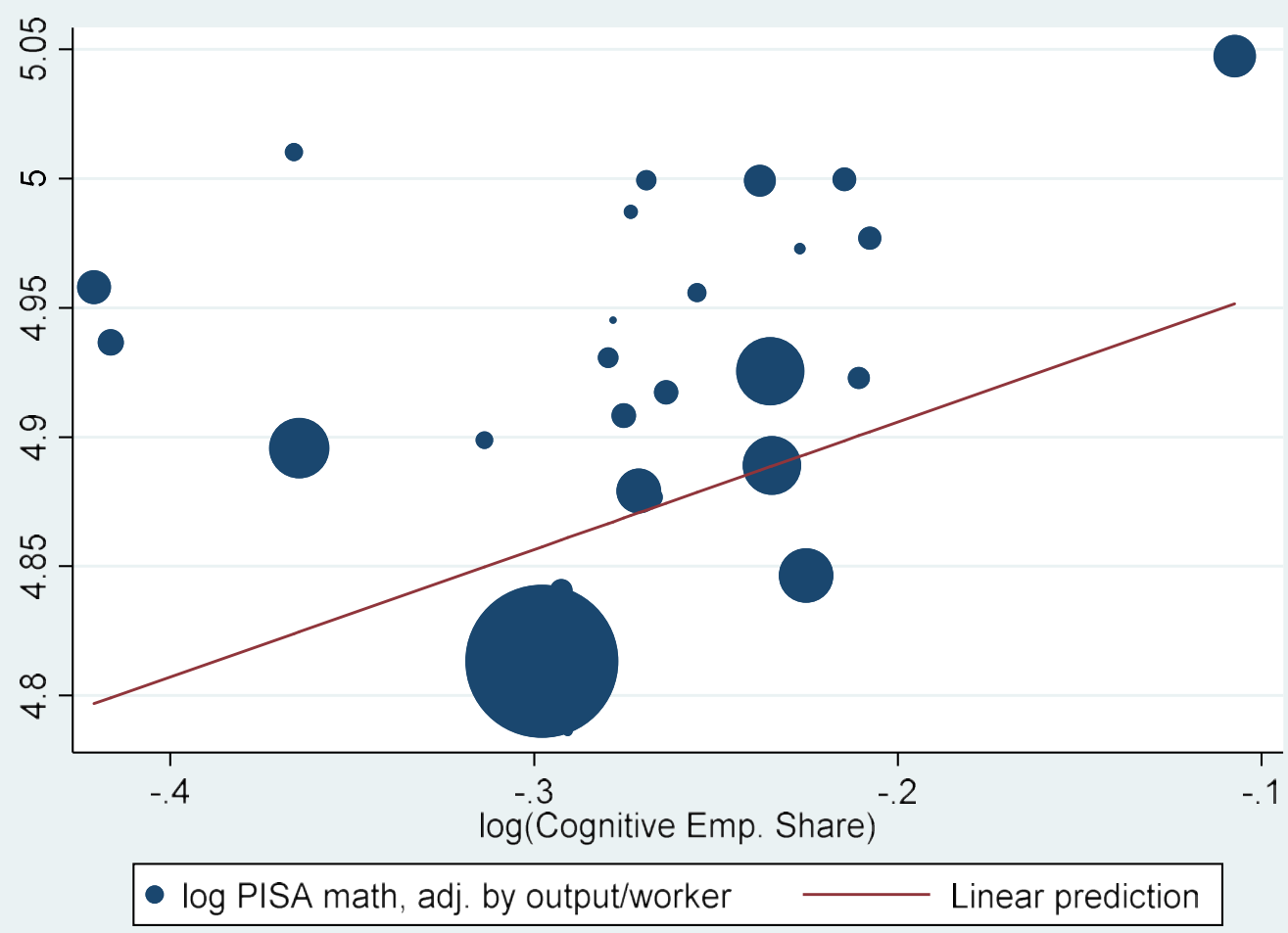

2b. Expanded Sample

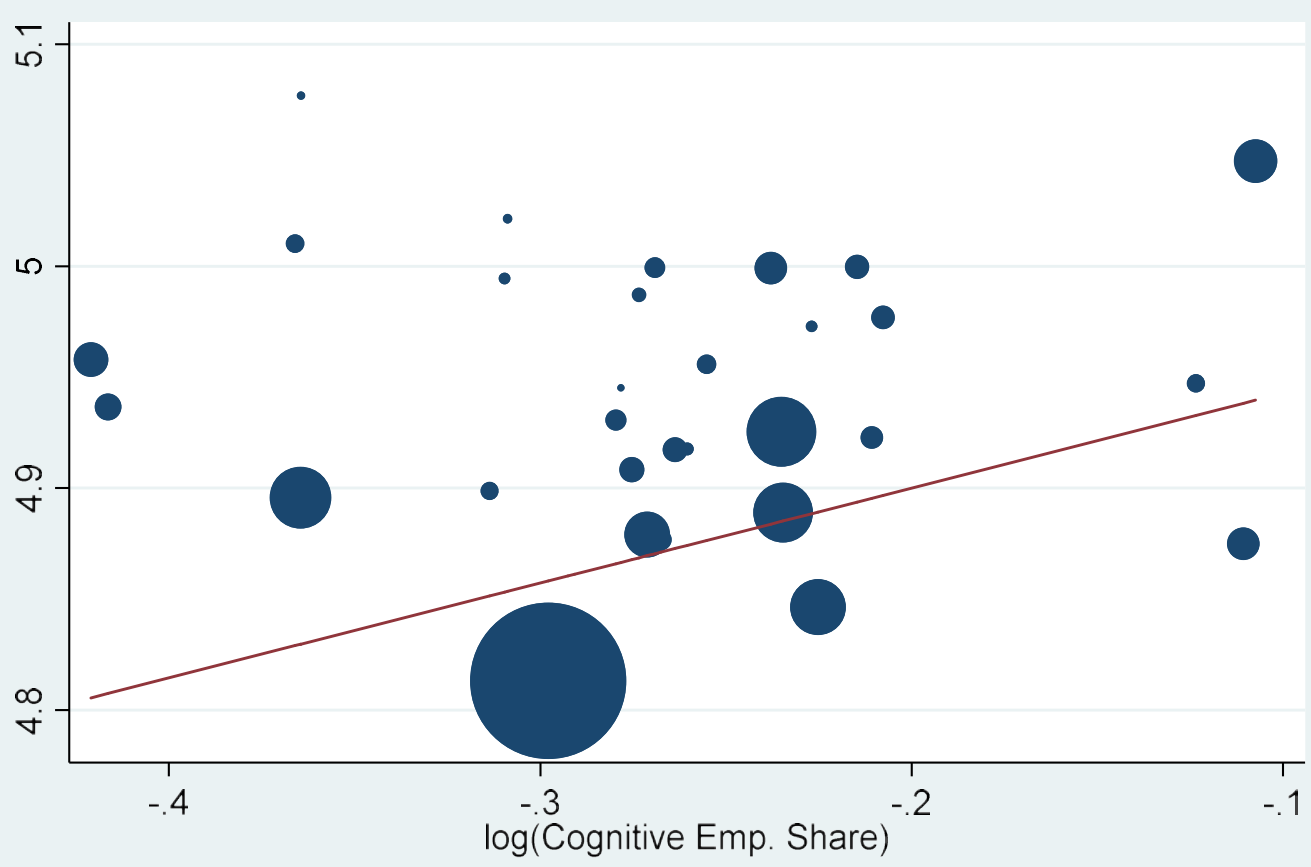

- log PISA math, adj. by output/worker — Linear prediction 
Figure 3 Cognitive-Productivity Ranking vs. PISA-Math Ranking

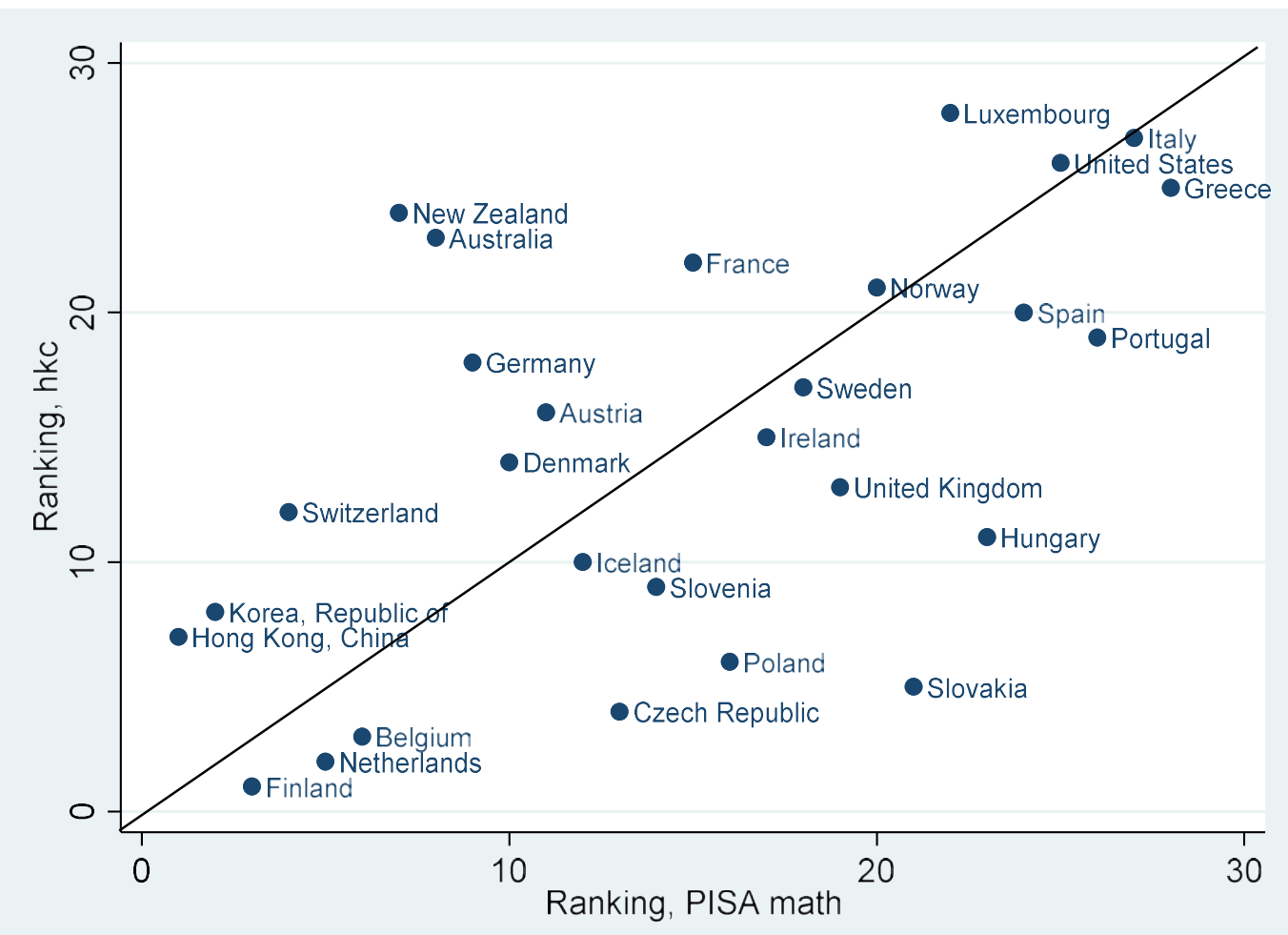

Figure 4 Non-Cognitive-Productivity Ranking vs. PISA-Math Ranking

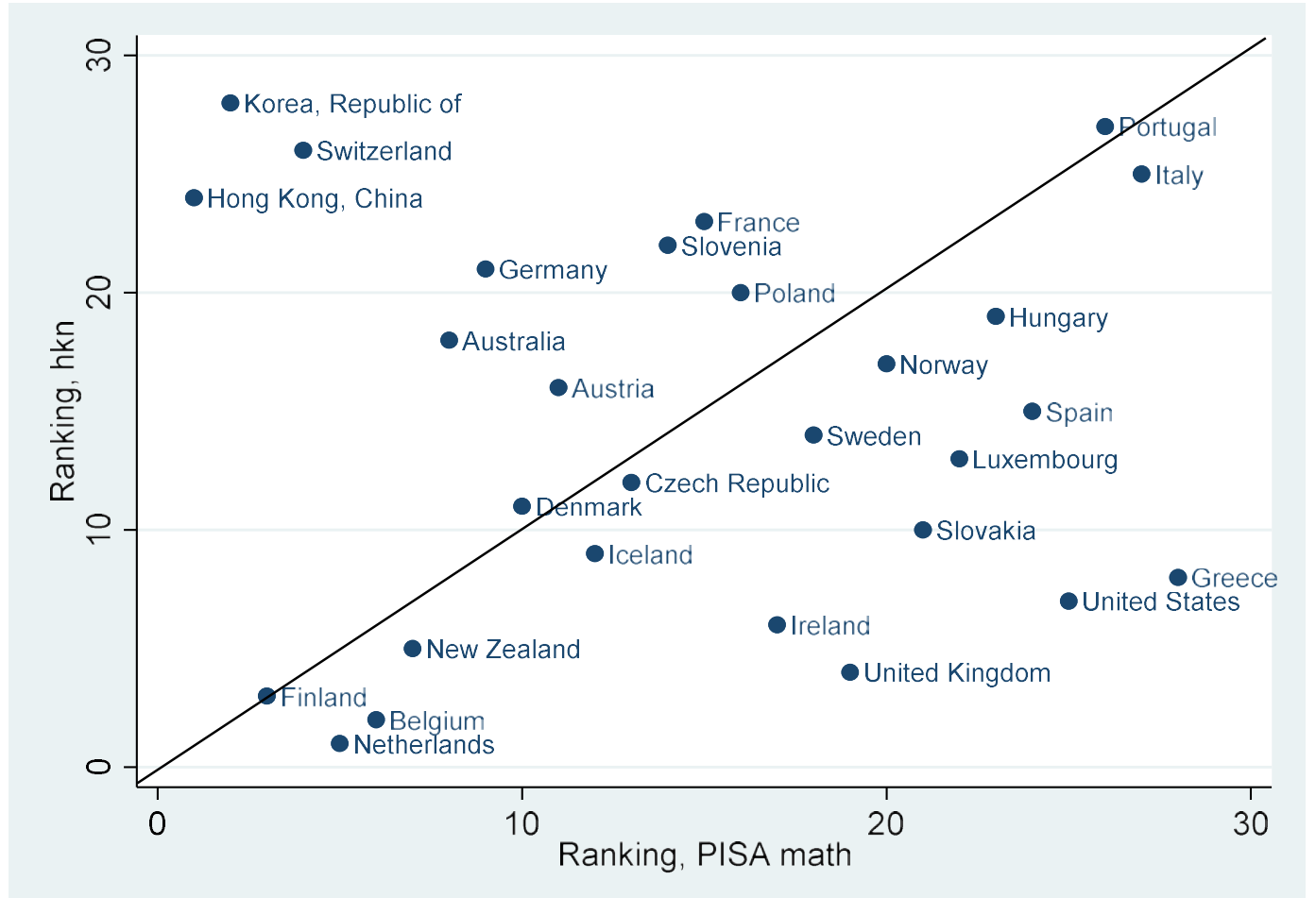


Figure 5 Iso-HCQI Curve

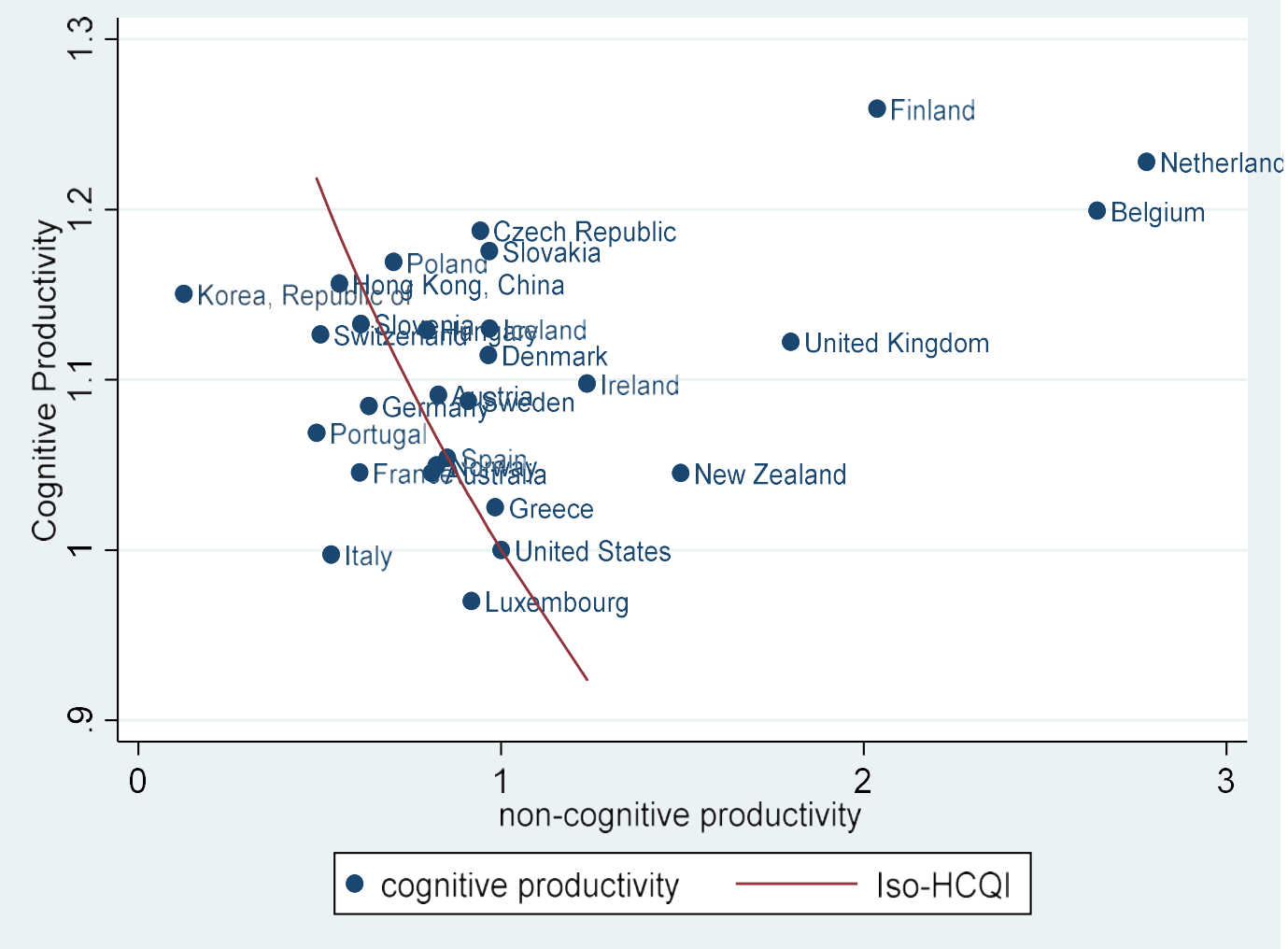

Figure 6 Iso-HCQI Curve, Free-trade

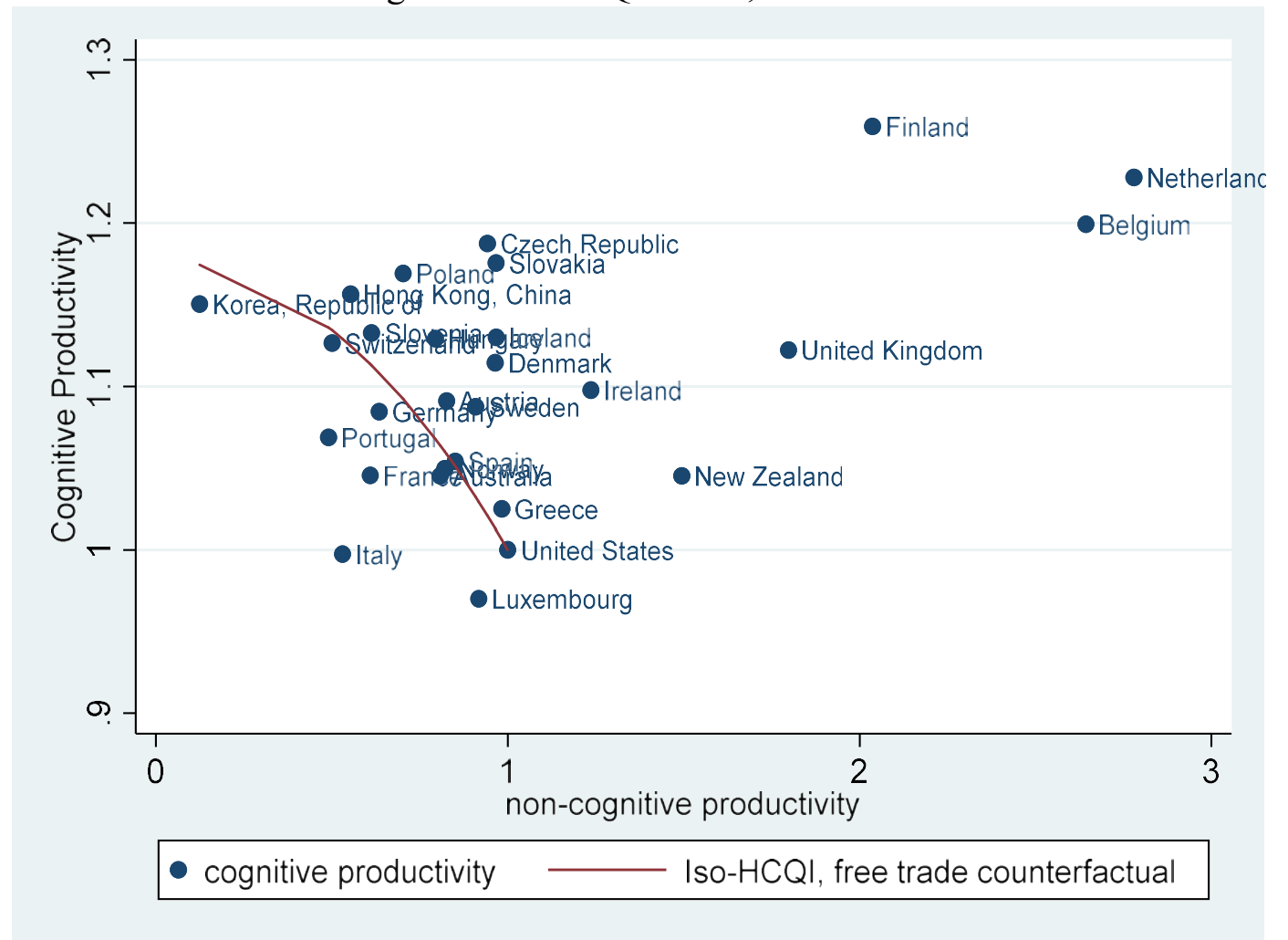


Figure 7 Changes in HCQI, Autarky to Free Trade

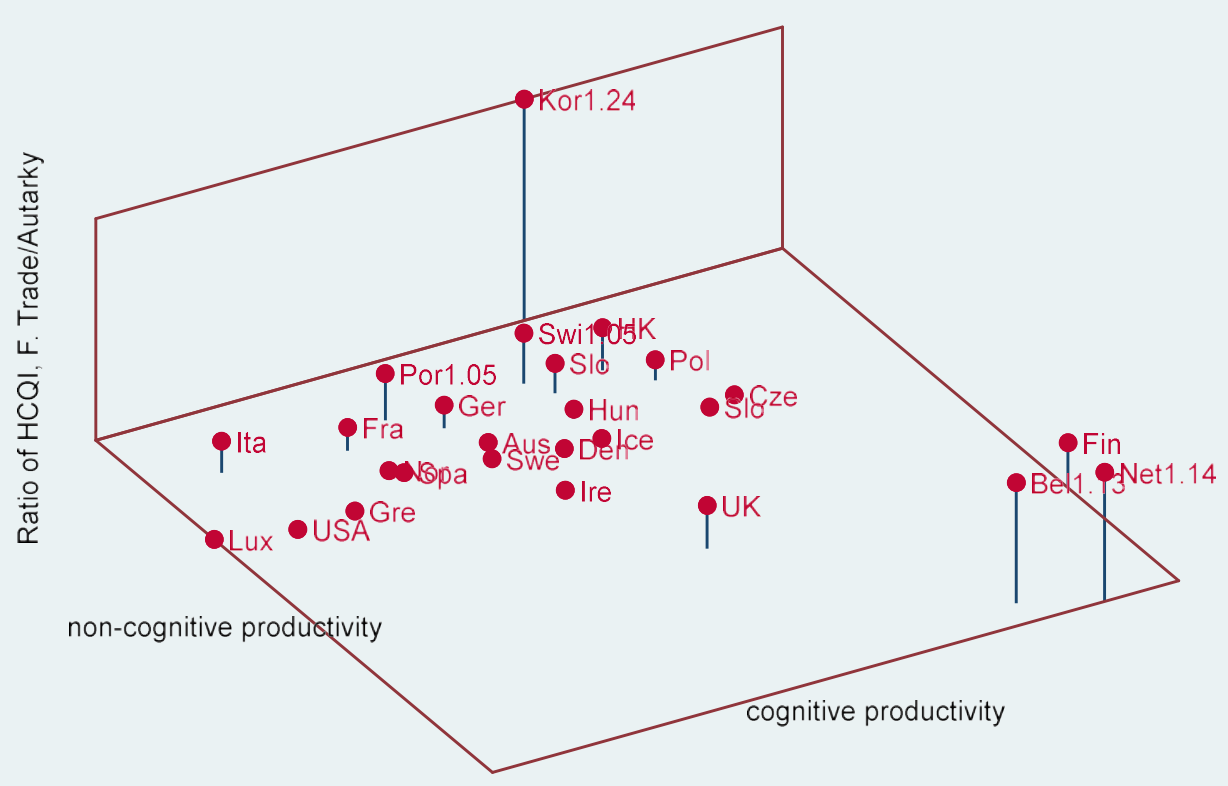

Figure 8 Immigrants' Non-cognitive Share vs. Comparative Advantage

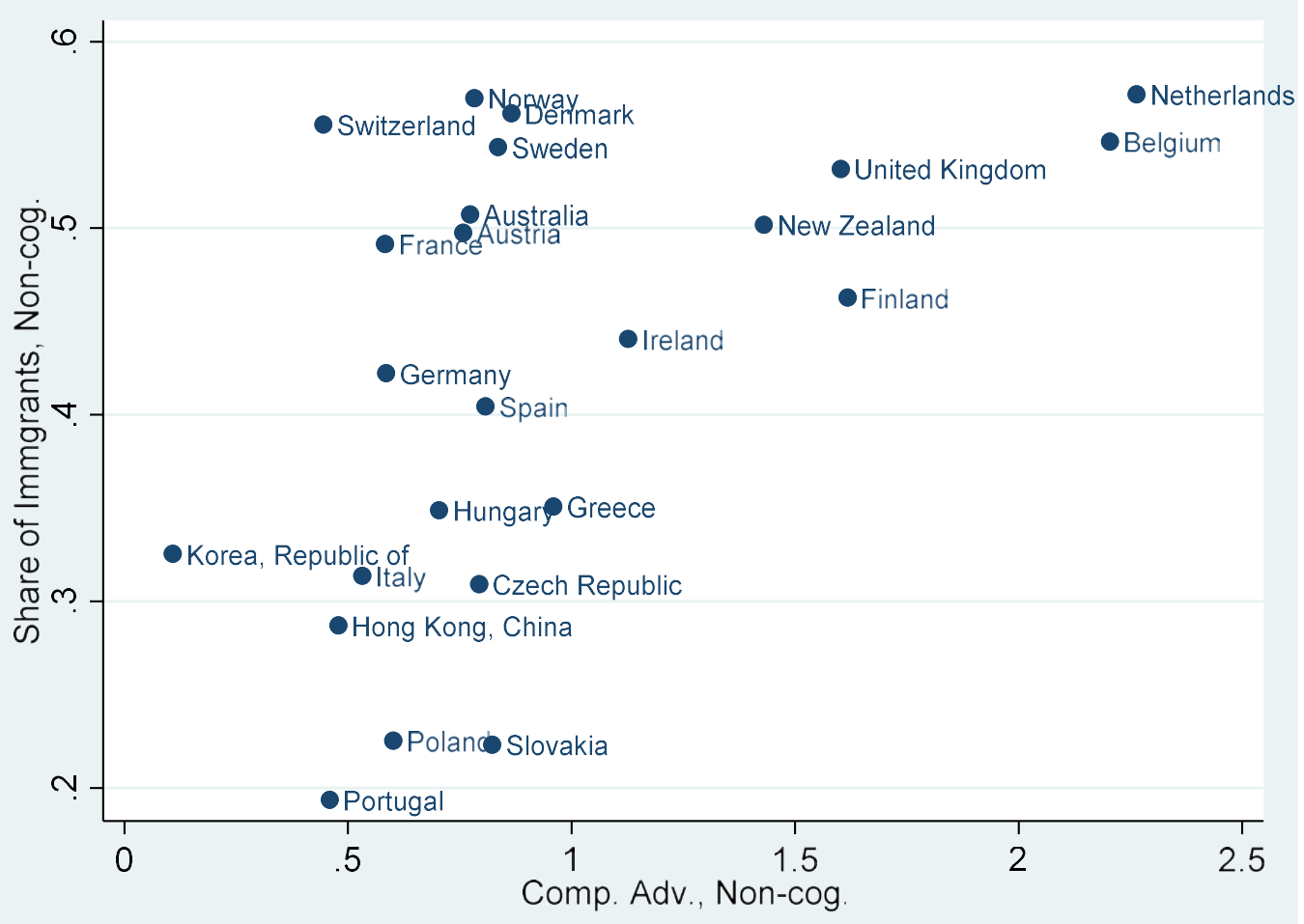


Table 1 AFQT Score and Wages of Non-cognitive and Cognitive Occupations

\begin{tabular}{|c|c|c|c|c|c|c|c|}
\hline VARIABLES & Replicate & $\begin{array}{c}(2) \\
\text { Non-Cog. } \\
\text { SubSample }\end{array}$ & $\begin{array}{c}(3) \\
\text { Cog. } \\
\text { SubSample }\end{array}$ & Interaction & $\begin{array}{c}(5) \\
\text { Guide \& } \\
\text { Direct }\end{array}$ & Enterprising & $\begin{array}{c}(7) \\
\text { Full } \\
\text { Sample }\end{array}$ \\
\hline Black & $\begin{array}{c}-0.0537 * * * \\
(0.0196)\end{array}$ & $\begin{array}{c}-0.0740^{* *} \\
(0.0355)\end{array}$ & $\begin{array}{c}-0.0462^{* *} \\
(0.0230)\end{array}$ & $\begin{array}{c}-0.0656 * * * \\
(0.0191)\end{array}$ & $\begin{array}{c}-0.0661 * * * \\
(0.0191)\end{array}$ & $\begin{array}{c}-0.0641 * * * \\
(0.0192)\end{array}$ & $\begin{array}{c}-0.0522^{* * *} \\
(0.0195)\end{array}$ \\
\hline Hispanics & $\begin{array}{c}0.0425^{* *} \\
(0.0211)\end{array}$ & $\begin{array}{c}0.0276 \\
(0.0375)\end{array}$ & $\begin{array}{l}0.0455^{*} \\
(0.0251)\end{array}$ & $\begin{array}{c}0.0424 * * \\
(0.0205)\end{array}$ & $\begin{array}{c}0.0413 * * \\
(0.0206)\end{array}$ & $\begin{array}{c}0.0414 * * \\
(0.0206)\end{array}$ & $\begin{array}{c}0.0433 * * \\
(0.0211)\end{array}$ \\
\hline Age & $\begin{array}{c}0.0349 * * * \\
(0.00708)\end{array}$ & $\begin{array}{c}0.0465 * * * \\
(0.0126)\end{array}$ & $\begin{array}{c}0.0286 * * * \\
(0.00839)\end{array}$ & $\begin{array}{l}0.0320 * * * \\
(0.00687)\end{array}$ & $\begin{array}{c}0.0323 * * * \\
(0.00689)\end{array}$ & $\begin{array}{l}0.0316 * * * \\
(0.00690)\end{array}$ & $\begin{array}{c}0.0202 * * * \\
(0.00710)\end{array}$ \\
\hline Non-cog. Occp. & & & & $\begin{array}{c}0.131 * * * \\
(0.0163)\end{array}$ & $\begin{array}{c}0.121 * * * \\
(0.0163)\end{array}$ & $\begin{array}{c}0.127 * * * \\
(0.0186)\end{array}$ & \\
\hline College & & & & $\begin{array}{c}0.179 * * * \\
(0.0265)\end{array}$ & $\begin{array}{l}0.187 * * * \\
(0.0264)\end{array}$ & $\begin{array}{c}0.195 * * * \\
(0.0263)\end{array}$ & \\
\hline AFQT & $\begin{array}{l}0.183 * * * \\
(0.00964)\end{array}$ & $\begin{array}{c}0.146 * * * \\
(0.0179)\end{array}$ & $\begin{array}{c}0.183 * * * \\
(0.0114)\end{array}$ & $\begin{array}{l}0.140 * * * \\
(0.0115)\end{array}$ & $\begin{array}{c}0.137 * * * \\
(0.0115)\end{array}$ & $\begin{array}{c}0.125^{* * *} \\
(0.0113)\end{array}$ & \\
\hline $\mathrm{AFQT}^{2}$ & $\begin{array}{l}-0.0130 \\
(0.00802)\end{array}$ & $\begin{array}{l}-0.0185 \\
(0.0140)\end{array}$ & $\begin{array}{l}-0.00453 \\
(0.00971)\end{array}$ & $\begin{array}{c}-0.0356^{* * * *} \\
(0.00948)\end{array}$ & $\begin{array}{c}-0.0369 * * * \\
(0.00950)\end{array}$ & $\begin{array}{c}-0.0358 * * * \\
(0.00956)\end{array}$ & \\
\hline AFQT x Non-Cog. & & & & $\begin{array}{c}-0.0541 * * * \\
(0.0160)\end{array}$ & $\begin{array}{c}-0.0345 * * \\
(0.0159)\end{array}$ & $\begin{array}{r}-0.00749 \\
(0.0182)\end{array}$ & \\
\hline AFQT x College & & & & $\begin{array}{c}0.0582 * * \\
(0.0245)\end{array}$ & $\begin{array}{c}0.0525 * * \\
(0.0245)\end{array}$ & $\begin{array}{c}0.0495 * * \\
(0.0244)\end{array}$ & \\
\hline $\log ($ AFQT PISA Scale) & & & & & & & $\begin{array}{l}0.912 * * * \\
(0.0437)\end{array}$ \\
\hline Constant & $\begin{array}{c}6.233 * * * \\
(0.112)\end{array}$ & $\begin{array}{c}6.178^{* * * *} \\
(0.199)\end{array}$ & $\begin{array}{c}6.276 * * * \\
(0.133)\end{array}$ & $\begin{array}{c}6.218^{* * *} \\
(0.109)\end{array}$ & $\begin{array}{c}6.218 * * * \\
(0.109)\end{array}$ & $\begin{array}{c}6.232 * * * \\
(0.109)\end{array}$ & $\begin{array}{c}0.798 * * * \\
(0.283)\end{array}$ \\
\hline $\begin{array}{l}\text { Obs. No. } \\
\mathrm{R}^{2}\end{array}$ & $\begin{array}{l}3,210 \\
0.168\end{array}$ & $\begin{array}{c}973 \\
0.130\end{array}$ & $\begin{array}{l}2,237 \\
0.167\end{array}$ & $\begin{array}{l}3,210 \\
0.217\end{array}$ & $\begin{array}{l}3,210 \\
0.214\end{array}$ & $\begin{array}{l}3,210 \\
0.211\end{array}$ & $\begin{array}{l}3,210 \\
0.169\end{array}$ \\
\hline
\end{tabular}

Notes: The dependent variable is log wage, and the sample is NLSY 79. Standard errors in parentheses. $* * * \mathrm{p}<0.01, * * \mathrm{p}<0.05, *$ $\mathrm{p}<0.1$. Columns (1)-(3) are discussed in section 2, (4)-(6) in sections 2 and 5, and column (7) in section 8. 
Table 2 Summary Statistics

\begin{tabular}{|c|c|c|c|c|c|}
\hline & Obs & Mean & Std. Dev. & Min & Max \\
\hline \multicolumn{6}{|l|}{ Main Sample } \\
\hline Labor Force Size & 28 & 12541.24 & 23132.62 & 156.43 & 120464.70 \\
\hline Non-cog. Emp. Share & 28 & 0.2448 & 0.0565 & 0.1018 & 0.3775 \\
\hline Cognitive Emp. Share & 28 & 0.7552 & 0.0565 & 0.6225 & 0.8982 \\
\hline Total Output $(\$ 000)$ & 28 & $4.69 \mathrm{E}+08$ & $1.19 \mathrm{E}+09$ & 4196242 & $6.32 \mathrm{E}+09$ \\
\hline Edu. Exp./Output & 20 & 0.1255 & 0.0194 & 0.0985 & 0.1695 \\
\hline PISA Reading Score & 28 & 498.96 & 18.30 & 468.93 & 539.34 \\
\hline PISA Math Score & 28 & 503.73 & 22.17 & 455.80 & 553.40 \\
\hline PISA Science Score & 28 & 506.81 & 19.70 & 470.07 & 554.28 \\
\hline |Net Cog. Exp.| & 28 & 0.0158 & 0.0127 & 0.00004 & 0.0458 \\
\hline |Net Non-cog. Exp.| & 28 & 0.0286 & 0.0257 & 0.0008 & 0.1002 \\
\hline \multicolumn{6}{|l|}{ Expanded Sample } \\
\hline Labor Force Size & 34 & 11367.97 & 21312.48 & 156.43 & 120464.70 \\
\hline Non-cog. Emp. Share & 34 & 0.2395 & 0.0619 & 0.1018 & 0.3775 \\
\hline Cognitive Emp. Share & 34 & 0.7605 & 0.0619 & 0.6225 & 0.8982 \\
\hline Total Output (\$000) & 34 & $3.97 \mathrm{E}+08$ & $1.09 \mathrm{E}+09$ & 4196242 & $6.32 \mathrm{E}+09$ \\
\hline Edu. Exp./Output & 23 & 0.1228 & 0.0197 & 0.0960 & 0.1695 \\
\hline PISA Reading Score & 34 & 491.20 & 27.54 & 421.48 & 539.34 \\
\hline PISA Math Score & 34 & 495.93 & 30.55 & 419.84 & 553.40 \\
\hline PISA Science Score & 34 & 500.28 & 28.39 & 428.45 & 554.28 \\
\hline |Net Cog. Exp.| & 34 & 0.0410 & 0.0847 & 0.0000 & 0.4543 \\
\hline |Net Non-cog. Exp.| & 34 & 0.0677 & 0.1135 & 0.0008 & 0.5261 \\
\hline
\end{tabular}


Table 3 Main-Sample Countries, Years and Rankings

\begin{tabular}{lcccc} 
Country & Year & $\begin{array}{c}\text { Cog-Prod } \\
\text { Rank }\end{array}$ & $\begin{array}{c}\text { PISA Math } \\
\text { Rank }\end{array}$ & $\begin{array}{c}\text { Non-Cog } \\
\text { Prod Rank }\end{array}$ \\
\hline Australia & 2000 & 23 & 8 & 18 \\
Austria & 2000 & 16 & 11 & 16 \\
Belgium & 2000 & 3 & 6 & 2 \\
Czech Republic & 2000 & 4 & 13 & 12 \\
Denmark & 2000 & 14 & 10 & 11 \\
Finland & 2000 & 1 & 3 & 3 \\
France & 2000 & 22 & 15 & 23 \\
Germany & 2000 & 18 & 9 & 21 \\
Greece & 2000 & 25 & 28 & 8 \\
Hong Kong, China & 2001 & 7 & 1 & 24 \\
Hungary & 2000 & 11 & 23 & 19 \\
Iceland & 2000 & 10 & 12 & 9 \\
Ireland & 2000 & 15 & 17 & 6 \\
Italy & 2000 & 27 & 27 & 25 \\
Korea, Republic of & 2000 & 8 & 2 & 28 \\
Luxembourg & 2000 & 28 & 22 & 13 \\
Netherlands & 2000 & 2 & 5 & 1 \\
New Zealand & 1996 & 24 & 7 & 5 \\
Norway & 2000 & 21 & 20 & 17 \\
Poland & 2000 & 6 & 16 & 20 \\
Portugal & 2000 & 19 & 26 & 27 \\
Slovakia & 2000 & 5 & 21 & 10 \\
Slovenia & 2000 & 9 & 14 & 22 \\
Spain & 2000 & 20 & 24 & 15 \\
Sweden & 2000 & 17 & 18 & 14 \\
Switzerland & 1990 & 12 & 4 & 26 \\
United Kingdom & 2000 & 13 & 19 & 4 \\
United States & 2000 & 26 & 25 & 7 \\
\hline & & & & \\
\hline
\end{tabular}


Table 4 Normalized Test Score \& Cognitive Employment Share

\begin{tabular}{ccccccc}
\multicolumn{3}{c}{ Raw PISA Score } & & \multicolumn{2}{c}{ Scaled PISA Score } \\
\cline { 1 - 3 } \cline { 5 - 7 } & $(2)$ & $(3)$ & $(4)$ & & $(5)$ & $(6)$ \\
Leader. & Leader. & Guide \& & & & AFQT to & PISA to \\
P.C. & P.C. & Direct & Enterprising & & PISA & AFQT \\
\hline
\end{tabular}

\begin{tabular}{|c|c|c|c|c|c|c|}
\hline \multicolumn{2}{|c|}{ Main Sample } & \multirow[b]{2}{*}{$\begin{array}{c}0.493^{* *} \\
(0.219)\end{array}$} & \multirow[b]{2}{*}{$\begin{array}{c}0.668^{* * *} \\
(0.235)\end{array}$} & \multirow[b]{2}{*}{$\begin{array}{c}0.574 \\
(0.351)\end{array}$} & \multirow[b]{2}{*}{$\begin{array}{c}0.475^{* *} \\
(0.204)\end{array}$} & \multirow[b]{2}{*}{$\begin{array}{c}0.491 * * \\
(0.233)\end{array}$} \\
\hline $\ln \left(p_{c}{ }^{k}\right)$ & $\begin{array}{c}0.493^{* *} \\
(0.213)\end{array}$ & & & & & \\
\hline ASNZ & $\begin{array}{l}0.199^{* *} \\
(0.0757)\end{array}$ & & $\begin{array}{c}0.221^{* * * *} \\
(0.0738)\end{array}$ & $\begin{array}{l}0.185^{* *} \\
(0.0791)\end{array}$ & $\begin{array}{l}0.193 * * \\
(0.0724)\end{array}$ & $\begin{array}{l}0.209 * * \\
(0.0823)\end{array}$ \\
\hline $\begin{array}{c}\text { Obs. \# } \\
\mathrm{R}^{2}\end{array}$ & $\begin{array}{c}28 \\
0.277\end{array}$ & $\begin{array}{c}26 \\
0.175\end{array}$ & $\begin{array}{c}28 \\
0.337\end{array}$ & $\begin{array}{c}28 \\
0.208\end{array}$ & $\begin{array}{c}28 \\
0.282\end{array}$ & $\begin{array}{c}28 \\
0.255\end{array}$ \\
\hline \multicolumn{7}{|c|}{ Expanded Sample } \\
\hline $\ln \left(p_{c}{ }^{k}\right)$ & $\begin{array}{c}0.427 * * \\
(0.179)\end{array}$ & $\begin{array}{c}0.427^{* *} \\
(0.182)\end{array}$ & $\begin{array}{c}0.565^{* * *} \\
(0.198)\end{array}$ & $\begin{array}{l}0.558^{*} \\
(0.300)\end{array}$ & $\begin{array}{c}0.426^{* *} \\
(0.171)\end{array}$ & $\begin{array}{c}0.484 * * \\
(0.222)\end{array}$ \\
\hline ASNZ & $\begin{array}{c}0.193 * * * \\
(0.0693)\end{array}$ & & $\begin{array}{c}0.210^{* * * *} \\
(0.0682)\end{array}$ & $\begin{array}{l}0.184^{* *} \\
(0.0715)\end{array}$ & $\begin{array}{l}0.188^{* * *} \\
(0.0662)\end{array}$ & $\begin{array}{l}0.208^{* *} \\
(0.0788)\end{array}$ \\
\hline $\begin{array}{c}\text { Obs. \# } \\
\mathrm{R}^{2}\end{array}$ & $\begin{array}{c}34 \\
0.256\end{array}$ & $\begin{array}{c}32 \\
0.154\end{array}$ & $\begin{array}{c}34 \\
0.302\end{array}$ & $\begin{array}{c}34 \\
0.207\end{array}$ & $\begin{array}{c}34 \\
0.268\end{array}$ & $\begin{array}{c}31 \\
0.248\end{array}$ \\
\hline
\end{tabular}

Notes: The dependent variable is the log of PISA score normalized by output per worker to the power of $\eta=0.1255$. Standard errors in parentheses. ${ }^{* * *} \mathrm{p}<0.01,{ }^{* *} \mathrm{p}<0.05,{ }^{*} \mathrm{p}<0.1$. ASNZ is the dummy for Australia and New Zealand. Columns (1)-(4) are discussed in section 5, and (5)(6) in section 8. 
Table 5 Parameter Values under Various Specifications

\begin{tabular}{lcccccc} 
& \multicolumn{2}{c}{ Values } & & \multicolumn{3}{c}{ Correlation Coefficients } \\
\cline { 2 - 3 } \cline { 5 - 6 } & & & & & \multicolumn{3}{c}{$\begin{array}{c}\text { Non- } \\
\text { Cognitive } \\
\text { cognitive }\end{array}$} \\
\hline (1) Benchmark & 1.973 & 1.676 & & 1.000 & 1.000 & 1.000 \\
$\quad$ (2) Non-cog. Component & 1.973 & 1.676 & & 0.000 & 1.000 & 0.947 \\
(3) Guide \& Direct & 3.014 & 1.491 & & 0.991 & 0.967 & 0.967 \\
(4) Expanded Sample & 1.746 & 1.438 & & 0.998 & 0.991 & 0.996 \\
(5) Trade & 1.973 & 1.726 & & 1.000 & 1.000 & 0.918 \\
(6) PISA Scaled & 1.904 & 1.684 & & 0.999 & 1.000 & 0.999 \\
(7) Alt. $\theta \& \alpha$ values & 4.000 & 2.000 & & 0.970 & 0.994 & 0.995 \\
\hline
\end{tabular}


Table 6 Summary of Main Parameters and Their Benchmark Values

\begin{tabular}{|c|c|c|c|c|}
\hline Parameter & Intuition & Value & Target & Value in Literature \\
\hline & Elasticity in Human Cap & & & \\
\hline$\eta$ & Prod & 0.126 & Edu. spending as share of output, (25) & \\
\hline & Dispersion of Innate & & Correlation btw. normalized PISA score & \\
\hline$\theta$ & Ability & 1.973 & and cog. emp. share, $(26)$ & 2 (Hsieh et al. 2018) \\
\hline & Sub Elasticity in Agg. & & & \\
\hline$\alpha$ & Production & 1.676 & Agg. prod. function, (27) & 1.78 (Burnstein et al. 2016) \\
\hline$\Theta^{k}$ & Output TFP & Table 8 & Residual of (27), given $\alpha$ & Data Appendix 6 \\
\hline$h_{c}^{k}$ & $\begin{array}{l}\text { TFP of Cog.-H.-Cap. } \\
\text { Production }\end{array}$ & Figure 4 & $\begin{array}{l}\text { Normalized test score net of cog. emp. } \\
\text { share, given } \theta \text { and } \eta,(26)\end{array}$ & \\
\hline$h_{n}^{k}$ & $\begin{array}{l}\text { TFP of Non-Cog.-H.-Cap. } \\
\text { Production }\end{array}$ & Figure 4 & $\begin{array}{l}\text { Revealed comp. advantage by relative } \\
\text { emp. share, given } \alpha, \theta \text { and } h_{c}^{k},(20)\end{array}$ & \\
\hline
\end{tabular}


Table 7 Output/Cognitive Human Capital \& Relative Quantity of Non-cognitive Human Capital

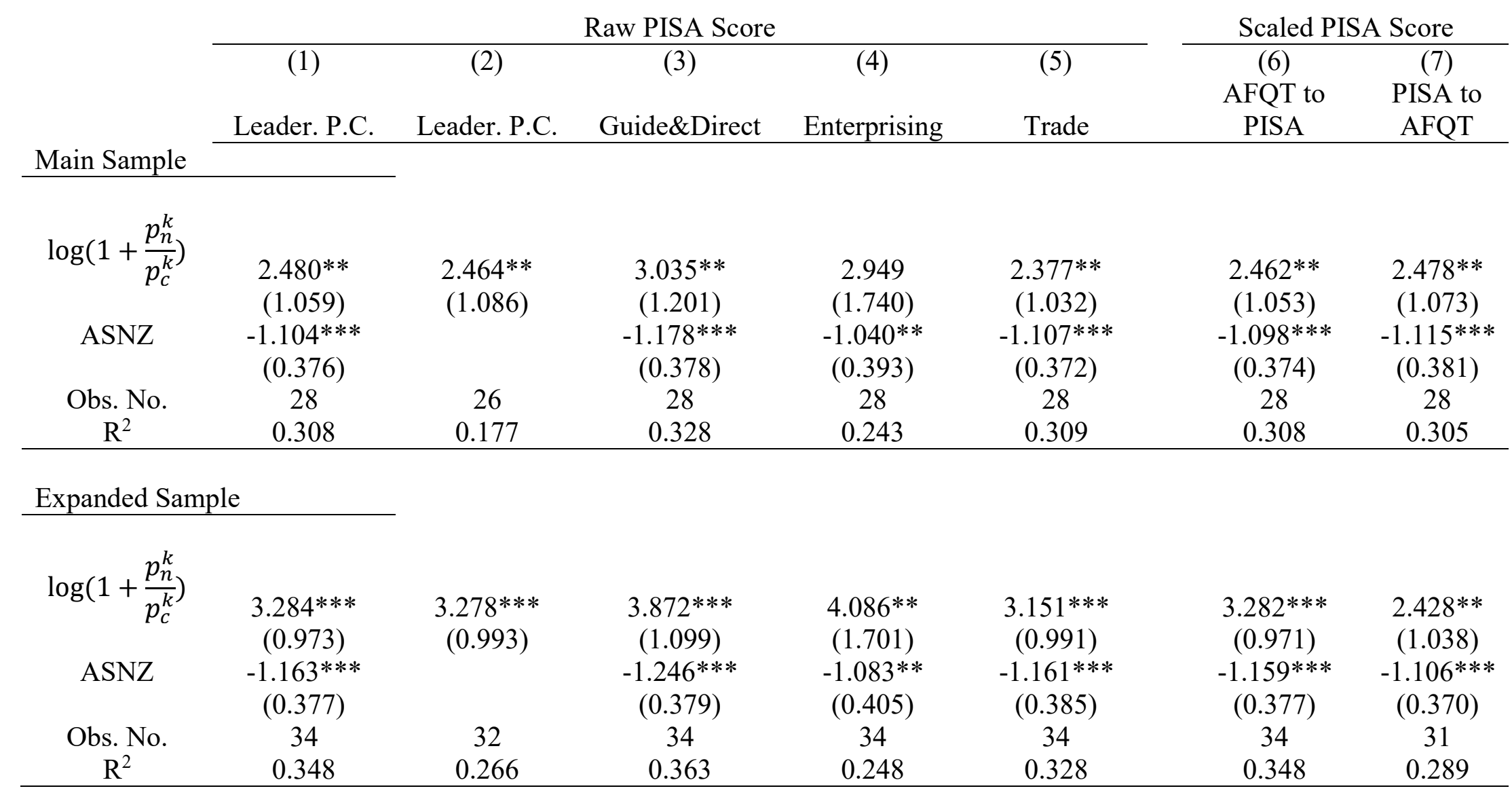

Notes: The dependent variable is the log of output per worker divided by PISA score. Standard errors in parentheses. $* * * \mathrm{p}<0.01, * *$ $\mathrm{p}<0.05, * \mathrm{p}<0.1$. ASNZ is the dummy for Australia and New Zealand. Columns (1)-(4) are discussed in section 5, column (5) in section 7 , and (6)-(7) in section 8 . 
Table 8 HCQI and Output per Worker

\begin{tabular}{|c|c|c|c|c|c|c|}
\hline \multirow[b]{3}{*}{ Countries } & \multicolumn{3}{|c|}{ Decomposition } & \multicolumn{2}{|c|}{$\%$ Output change } & \multirow{3}{*}{$\begin{array}{c}\text { Trade } \\
6 \\
\text { Contribution } \\
\text { of HCQI }\end{array}$} \\
\hline & 1 & 2 & 3 & 4 & 5 & \\
\hline & $\begin{array}{l}\text { Output Per } \\
\text { Worker }\end{array}$ & $\begin{array}{c}\text { Contribution } \\
\text { of Output } \\
\text { TFP }\end{array}$ & $\begin{array}{c}\text { Contribution of } \\
\text { HCQI }\end{array}$ & $\begin{array}{l}\text { 1\% Rise in } \\
h_{c}{ }^{k}\end{array}$ & $\begin{array}{l}\text { 1\% Rise in } \\
\mathrm{h}_{\mathrm{n}}{ }^{\mathrm{k}}\end{array}$ & \\
\hline Austria & 0.6434 & 0.6294 & 1.0224 & $0.88 \%$ & $0.26 \%$ & 1.0029 \\
\hline Belgium & 0.6892 & 0.4277 & 1.6114 & $0.75 \%$ & $0.39 \%$ & 1.8103 \\
\hline Czech Republic & 0.3293 & 0.2888 & 1.1403 & $0.87 \%$ & $0.27 \%$ & 1.1038 \\
\hline Denmark & 0.5979 & 0.5505 & 1.0861 & $0.86 \%$ & $0.28 \%$ & 1.0733 \\
\hline Finland & 0.5037 & 0.3315 & 1.5196 & $0.79 \%$ & $0.35 \%$ & 1.4919 \\
\hline France & 0.7329 & 0.8041 & 0.9115 & $0.90 \%$ & $0.24 \%$ & 0.8607 \\
\hline Germany & 0.6296 & 0.6617 & 0.9515 & $0.90 \%$ & $0.24 \%$ & 0.8748 \\
\hline Greece & 0.5190 & 0.5106 & 1.0164 & $0.85 \%$ & $0.29 \%$ & 1.0405 \\
\hline Hong Kong, China & 0.6864 & 0.7021 & 0.9776 & $0.92 \%$ & $0.22 \%$ & 0.9535 \\
\hline Hungary & 0.3517 & 0.3372 & 1.0430 & $0.89 \%$ & $0.26 \%$ & 0.9982 \\
\hline Iceland & 0.5110 & 0.4645 & 1.1001 & $0.87 \%$ & $0.28 \%$ & 1.1498 \\
\hline Ireland & 0.6642 & 0.5759 & 1.1532 & $0.84 \%$ & $0.31 \%$ & 1.0343 \\
\hline Italy & 0.6761 & 0.7998 & 0.8453 & $0.91 \%$ & $0.23 \%$ & 0.7842 \\
\hline S. Korea & 0.4304 & 0.5652 & 0.7615 & $1.03 \%$ & $0.12 \%$ & 0.6259 \\
\hline Luxembourg & 1.4376 & 1.5127 & 0.9503 & $0.85 \%$ & $0.29 \%$ & 0.9748 \\
\hline Netherlands & 0.6712 & 0.4013 & 1.6729 & $0.75 \%$ & $0.39 \%$ & 1.8185 \\
\hline Norway & 0.7289 & 0.7388 & 0.9866 & $0.88 \%$ & $0.27 \%$ & 0.9915 \\
\hline Poland & 0.3045 & 0.2918 & 1.0436 & $0.90 \%$ & $0.24 \%$ & 1.0007 \\
\hline Portugal & 0.3845 & 0.4343 & 0.8853 & $0.93 \%$ & $0.22 \%$ & 0.8436 \\
\hline Slovakia & 0.2979 & 0.2617 & 1.1383 & $0.87 \%$ & $0.27 \%$ & 1.1007 \\
\hline Slovenia & 0.3929 & 0.4003 & 0.9816 & $0.91 \%$ & $0.23 \%$ & 0.9207 \\
\hline Spain & 0.6087 & 0.6088 & 0.9997 & $0.87 \%$ & $0.27 \%$ & 0.9826 \\
\hline Sweden & 0.5937 & 0.5676 & 1.0459 & $0.87 \%$ & $0.27 \%$ & 0.9693 \\
\hline
\end{tabular}


Table 8 Continued

\begin{tabular}{|c|c|c|c|c|c|}
\hline & \multicolumn{2}{|c|}{ Decomposition } & \multicolumn{2}{|c|}{$\%$ Output } & \multirow{2}{*}{$\begin{array}{c}\text { Trade } \\
6\end{array}$} \\
\hline 1 & 2 & 3 & 4 & 5 & \\
\hline $\begin{array}{c}\text { Output Per } \\
\text { Worker }\end{array}$ & $\begin{array}{c}\text { Contribution } \\
\text { of Output } \\
\text { TFP } \\
\end{array}$ & $\begin{array}{c}\text { Contribution of } \\
\text { HCQI }\end{array}$ & $\begin{array}{c}1 \% \text { Rise in } \\
h_{k}{ }^{c}\end{array}$ & $\begin{array}{c}\text { 1\% Rise in } \\
h_{k}{ }^{n}\end{array}$ & $\begin{array}{c}\text { Contribution } \\
\text { of HCQI }\end{array}$ \\
\hline 0.5855 & 0.6270 & 0.9338 & $0.93 \%$ & $0.21 \%$ & 0.8197 \\
\hline 0.6349 & 0.4782 & 1.3277 & $0.79 \%$ & $0.35 \%$ & 1.4006 \\
\hline 1.0000 & 1.0000 & 1.0000 & $0.85 \%$ & $0.29 \%$ & 1.0000 \\
\hline
\end{tabular}


Table 9 HCQI, PISA Score \& Output per worker

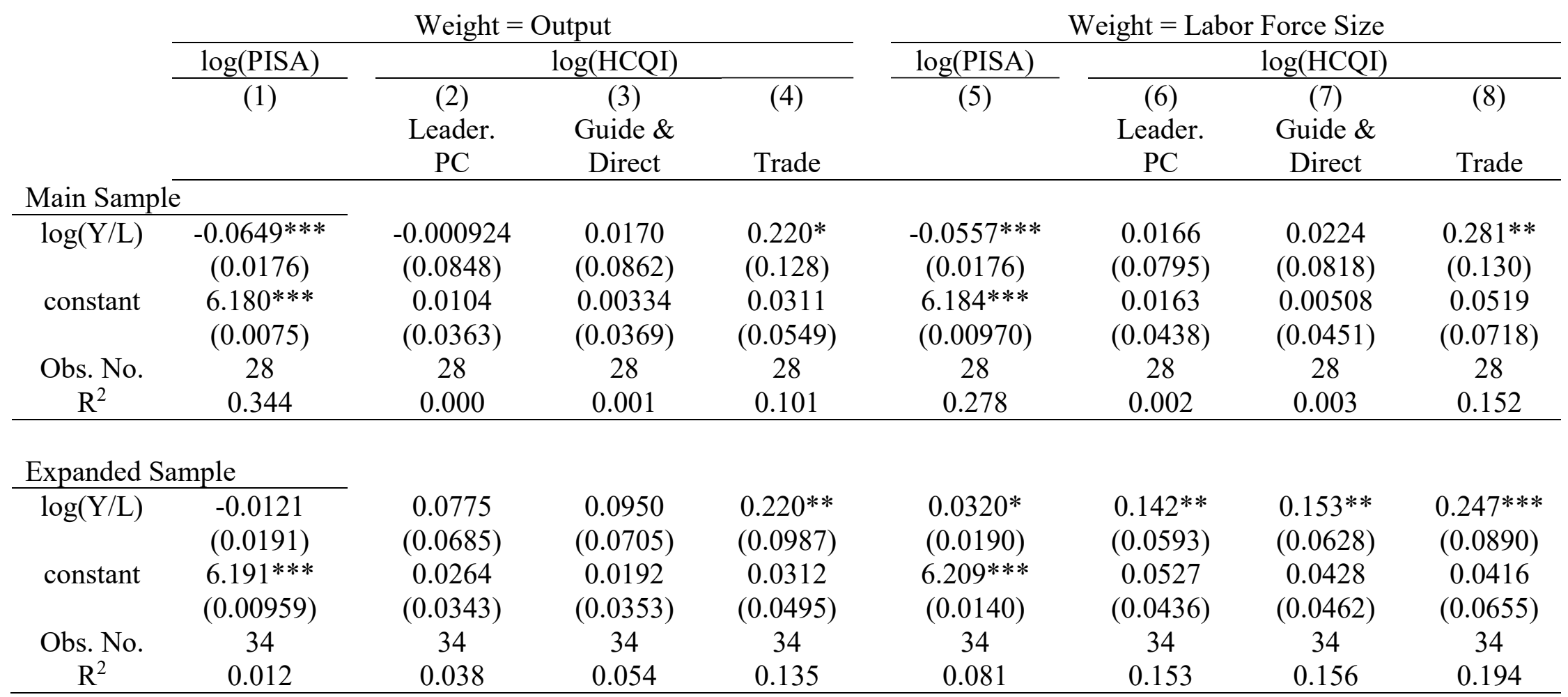

Notes: The dependent variable is the log of PISA score in columns (1) and (5), and $\log (\mathrm{HCQI})$ in the other columns. Standard errors in parentheses. ${ }^{* * *} \mathrm{p}<0.01, * * \mathrm{p}<0.05, * \mathrm{p}<0.1$. Columns (1)-(3) and (5)-(7) are discussed in section 6, and columns (4) and (8) in section 7. 
Table 10 Counterfactual Exercises for the Free-Trade Equilibrium

\begin{tabular}{|c|c|c|c|c|}
\hline \multirow[b]{2}{*}{ Countries } & \multirow{2}{*}{$\begin{array}{l}\text { Change in } \\
\text { HCQI } \\
\text { (1) }\end{array}$} & \multirow{2}{*}{$\begin{array}{c}\text { Gains } \\
\text { From } \\
\text { Trade } \\
\\
\\
(2)\end{array}$} & \multicolumn{2}{|c|}{$\%$ Output, Free Trade } \\
\hline & & & $\begin{array}{c}1 \% \text { Rise } \\
\text { in } h_{c}{ }^{k} \\
(3)\end{array}$ & $\begin{array}{c}1 \% \text { Rise in } \\
\mathrm{h}_{\mathrm{n}}{ }^{\mathrm{k}} \\
(4)\end{array}$ \\
\hline Austria & 1.0054 & 1.0067 & $0.94 \%$ & $0.21 \%$ \\
\hline Belgium & 1.1322 & 1.1533 & $0.41 \%$ & $0.72 \%$ \\
\hline Czech Republic & 1.0032 & 1.0043 & $0.92 \%$ & $0.22 \%$ \\
\hline Denmark & 1.0004 & 1.0011 & $0.89 \%$ & $0.26 \%$ \\
\hline Finland & 1.0489 & 1.0568 & $0.58 \%$ & $0.56 \%$ \\
\hline France & 1.0252 & 1.0294 & $1.01 \%$ & $0.14 \%$ \\
\hline Germany & 1.0248 & 1.0290 & $1.00 \%$ & $0.14 \%$ \\
\hline Greece & 0.9995 & 1.0001 & $0.85 \%$ & $0.30 \%$ \\
\hline Hong Kong & 1.0462 & 1.0537 & $1.05 \%$ & $0.09 \%$ \\
\hline Hungary & 1.0097 & 1.0118 & $0.96 \%$ & $0.18 \%$ \\
\hline Iceland & 1.0006 & 1.0013 & $0.90 \%$ & $0.25 \%$ \\
\hline Ireland & 1.0043 & 1.0055 & $0.77 \%$ & $0.37 \%$ \\
\hline Italy & 1.0344 & 1.0400 & $1.03 \%$ & $0.12 \%$ \\
\hline S. Korea & 1.2432 & 1.2834 & $1.13 \%$ & $0.01 \%$ \\
\hline Luxembourg & 0.9995 & 1.0000 & $0.85 \%$ & $0.29 \%$ \\
\hline Netherlands & 1.1415 & 1.1641 & $0.41 \%$ & $0.72 \%$ \\
\hline Norway & 1.0038 & 1.0049 & $0.93 \%$ & $0.22 \%$ \\
\hline Poland & 1.0222 & 1.0261 & $1.00 \%$ & $0.14 \%$ \\
\hline Portugal & 1.0511 & 1.0593 & $1.06 \%$ & $0.09 \%$ \\
\hline Slovakia & 1.0018 & 1.0027 & $0.91 \%$ & $0.24 \%$ \\
\hline Slovenia & 1.0326 & 1.0380 & $1.03 \%$ & $0.12 \%$ \\
\hline Spain & 1.0025 & 1.0035 & $0.91 \%$ & $0.23 \%$ \\
\hline Sweden & 1.0013 & 1.0021 & $0.90 \%$ & $0.24 \%$ \\
\hline Switzerland & 1.0550 & 1.0637 & $1.06 \%$ & $0.08 \%$ \\
\hline United Kingdom & 1.0471 & 1.0547 & $0.61 \%$ & $0.52 \%$ \\
\hline United States & 1.0000 & 1.0006 & $0.84 \%$ & $0.31 \%$ \\
\hline
\end{tabular}


Table 11 Normalized Net Exports \& Relative Abundance in Non-cognitive Human Capital

\begin{tabular}{|c|c|c|c|}
\hline & (1) & (2) & (3) \\
\hline \multicolumn{4}{|l|}{ Main Sample } \\
\hline Non-cog abundance $\mathrm{x}$ non-cog intensity & $\begin{array}{c}1.636^{* * * *} \\
(0.43)\end{array}$ & $\begin{array}{c}1.635^{* * * *} \\
(0.43)\end{array}$ & $\begin{array}{c}1.090 * * * \\
(0.41)\end{array}$ \\
\hline Cap abundance $\mathrm{x}$ cap intensity & & $\begin{array}{l}0.000 \\
(0.00)\end{array}$ & $\begin{array}{l}0.000 \\
(0.00)\end{array}$ \\
\hline Skill abundance $\mathrm{x}$ skill intensity & & & $\begin{array}{c}9.122 * * * \\
(1.97)\end{array}$ \\
\hline industry FE & yes & yes & yes \\
\hline country FE & yes & yes & yes \\
\hline $\mathrm{R}^{2}$ & 0.355 & 0.355 & 0.389 \\
\hline Obs. No. & 1103 & 1103 & 1103 \\
\hline \multicolumn{4}{|l|}{ Expanded Sample } \\
\hline Non-cog abundance $\mathrm{x}$ non-cog intensity & $\begin{array}{c}2.225^{* * *} \\
(0.45)\end{array}$ & $\begin{array}{c}2.147^{* * * *} \\
(0.44)\end{array}$ & $\begin{array}{c}1.157^{* * *} \\
(0.40)\end{array}$ \\
\hline Cap abundance $\mathrm{x}$ cap intensity & & $\begin{array}{l}0.000 \\
(0.00)\end{array}$ & $\begin{array}{l}0.000 \\
(0.00)\end{array}$ \\
\hline Skill abundance $\mathrm{x}$ skill intensity & & & $\begin{array}{c}9.010 * * * \\
(1.93)\end{array}$ \\
\hline industry FE & yes & yes & yes \\
\hline country FE & yes & yes & yes \\
\hline $\mathrm{R}^{2}$ & 0.31 & 0.314 & 0.376 \\
\hline Obs. No. & 1508 & 1508 & 1429 \\
\hline
\end{tabular}

Notes: The dependent variable is net export value divided by the sum of import and export values, by industry by country. Standard errors in parentheses. ${ }^{* * *} \mathrm{p}<0.01,{ }^{* *} \mathrm{p}<0.05,{ }^{*} \mathrm{p}<0.1$. 